\title{
Estimating the body mass of extinct ungulates: a study on the use of multiple regression
}

\author{
M. Mendoza ${ }^{1,2}$, C. M. Janis ${ }^{1} \&$ P. Palmqvist ${ }^{2}$ \\ 1 Department of Ecology and Evolutionary Biology, Brown University, Providence, RI, USA \\ 2 Departamento de Ecología y Geología, Facultad de Ciencias, Universidad de Málaga, Málaga, Spain
}

\section{Keywords}

body mass estimates; multiple regression; paleoautecology; extinct ungulates.

\section{Correspondence}

Manuel Mendoza, Department of Ecology and Evolutionary Biology, Box G-B207,

Brown University, Providence, RI 0291,

USA.

Email: mmendoza@fulbrightweb.org

Received 8 June 2005; accepted

16 November 2005

doi:10.1111/j.1469-7998.2006.00094.x

\begin{abstract}
The correlation between body mass and both skeletal and dental measures in living mammals has enabled paleontologists to obtain reliable estimates of body size for extinct species, usually using log-transformed bivariate least-squares regression equations. Multiple regression, however, has rarely been used for estimating the mass of extinct species, although this technique can clearly improve the predictive equations compared with those adjusted by simple regression. However, the use of multiple regression is problematical, because even those functions explaining a high percentage of the variance of the dependent variable (i.e. body mass) can show a rather limited predictive power. After analyzing which factors determine the predictive ability of multiple regression equations, we propose a new set of algorithms that allow the estimation of the body mass of extinct ungulates. These algorithms are finally applied to three Miocene ungulate species, Dinohippus leidyanus, Stenomylus hitchcocki and Aletomeryx scotti.
\end{abstract}

\section{Introduction}

Body mass is correlated with a plethora of physiological variables of animals (e.g. metabolic rates, heat flux and body temperature, metabolic costs of locomotion, growth and reproduction), with ecologically relevant characteristics (e.g. life-history traits, diet, population density, home range size and behavioral adaptations) and with larger-scale patterns in community structure and biogeography (e.g. Peters, 1983; Calder, 1984; Mendoza, 2004, 2005; Mendoza, Goodwin \& Criado, 2004; Mendoza, Janis \& Palmqvist, 2005). As a result, body mass has obvious implications on resource partitioning and ecological displacement among species that share the same dietary specializations, which translates into important ecological and evolutionary consequences. Because of these reasons, in recent years there has been growing interest in the paleobiological implications of body size in extinct mammals (see the chapters in Damuth \& MacFadden, 1990; Smith, 2002).

Obtaining accurate estimates of body size for extinct mammals, however, is a rather difficult task. The mass of extant species is grossly reflected in the size of their bones and teeth. Thus, separate regression analyses of body mass (dependent variable) on the dimensions of different skeletal parts (independent variables) allow the characterization of the relationship between skeletal morphology and body size for living species, and also the estimations of mass for extinct ones (Damuth, 1990). However, this approach is of limited value for estimating the size of extinct mammals, because the fossil record of most species is composed of only fragmentary remains, which precludes the use of those regression equations with higher levels of resolution and predictive power (e.g. head-body length, which measures the cylinder that encompasses the majority of the mammal's mass). In addition, given that teeth are more diagnostic of species identity than are other skeletal parts, and the prevalence of teeth in the fossil record (as these elements have the greatest fossilization potential because of their high structural density), most studies of ancient mammals are based on tooth measures (e.g. Janis, 1990a,b; Van Valkenburgh, 1990), although some attempts have been developed for estimating body mass from major limb bones (e.g. Gingerich, 1990; Scott, 1990; Anyonge, 1993; Kappelman et al., 1997; Biknevicius, 1999; Christiansen, 1999; Andersson, 2004).

\section{Theoretical basis for body mass estimation}

Some researchers have used external skeletal measures, such as the length and width of major limb bones (e.g. Alexander et al., 1979; Jungers, 1985, 1990; Christiansen, 2004), whereas others have focused on structural characteristics of these elements, such as the dimensions of their inner medullary cavities (e.g. Biewener, 1982; Ruff, 1987, 1988, 1989; Anyonge, 1993) or articular areas (e.g. Christiansen, 1999; Andersson, 2004). Postcranial dimensions are frequently better correlated with body mass than craniodental ones, especially cross-sectional measures of major limb bones, as 
they bear the animal's weight. Proximal bones (e.g. humerus and femur) are more useful for this purpose, because distal limb elements (e.g. radius, ulna, tibia and metapodials) are more related with morphological adaptations related to habitat preferences and mode of locomotion (Damuth \& MacFadden, 1990). Craniodental measures and body mass are also correlated, probably because of the relation between body size and the need to process a certain amount of food (Van Valen, 1960). But there are important differences among mammals with different diets (e.g. for a given body mass grazing ungulates have a significantly longer posterior skull than other feeding types; Janis, 1990a,b). However, the preservational bias of the fossil record in favor of teeth has resulted in the extensive use of dental measures in predictions of body mass in extinct mammalian species (e.g. Gingerich, Smith \& Rossenberg, 1982; Smith, 1984).

Some authors have used simple log-transformed bivariate least-squares regression equations, based on single anatomical measurements, to estimate the body mass of fossil species; for example, the occlusal area of the first lower molar (e.g. Beard et al., 1996; Gagnon, 1997; Kay, Johnson $\&$ Meldrum, 1998), the volume of the femoral head (Cartelle \& Hartwig, 1996; Kappelman et al., 1997) or the area of the orbit (Kordos \& Begun, 2001). However, no single morphological variable shows a perfect correlation with body mass, because skeletal and dental morphology is not only related to body size but is also constrained by the phylogenetic legacy and ecological adaptations (Damuth, 1990; Janis, $1990 b$ ). These factors reduce the correlation between any single morphological measure and body mass, and thus the precision and reliability of predictions derived from the use of such correlations, which becomes apparent in the large standard errors and wide confidence intervals usually obtained for the single regression equations.

Concerning the phylogenetic constraints, it is expected that taxonomically homogeneous groups of species (e.g. ungulate families) will show higher correlations between body mass and morphological measures than more heterogeneous clades (e.g. ungulate orders). However, when these algorithms are used for predicting the size of extinct ungulates, the regression functions obtained from a taxonomically restricted data set are applicable to fewer species than those derived from a taxonomically more diverse group, as these functions can only be applied with reliability to those species from the same taxonomic grouping used in their derivation. The reason is that those species from a taxonomically heterogeneous clade usually show numerous anatomical differences related to the phylogenetic legacy (i.e. lineage effects) and display a wide range of ecological adaptations. This translates into a greater morphological disparity than in the case of taxonomically homogeneous groups, which results in a weaker correlation between any single morphological variable and body mass.

More sophisticated studies combine mass estimates derived from a number of equations, based on several different anatomical structures (e.g. Walker et al., 1993; Flynn et al., 1995; Gebo et al., 1997; Fariña, Vizcaino \& Bargo, 1998; Christiansen, 1999; Delson et al., 2000). The seminal book edited by Damuth \& MacFadden (1990) compiles more than a thousand regression functions, and also provides many interesting theoretical considerations on the estimation of mammalian body size. Most of these equations are logtransformed bivariate regression functions of body mass on craniodental and postcranial measures, derived using the least-squares method (as body mass was assumed, for these purposes, to be invariate), and many of them have been used by other paleontologists (e.g. Fariña et al., 1998).

Because of the methodological limitations described above, the best estimate of body mass for extinct mammals is probably the arithmetic mean of the predictions obtained from several single regression equations (e.g. MacFadden, 1986; Gingerich, 1990; Anyonge, 1993; McCrossin, 1994; Viranta, 1994; Christiansen, 1999), although the geometric mean may be more accurate in those cases in which some estimates are clear outliers (see Fariña et al., 1998; Christiansen \& Fariña, 2003). Given that any morphological feature is influenced by the phylogeny and/or by functional adaptations, the assumption of all these studies is that such bias is compensated for by using several independent measures. However, the estimation of body mass by averaging the predictions obtained with different single measures is not appropriate from a statistical point of view. Although the number of morphological variables involved is greater, much of the information they contain is redundant, whereas the complementary information contained in other variables is wasted. In fact, this methodology is mathematically equivalent to using a multiple regression. The latter procedure, however, rules out the redundant information, while exploiting the complementary information contained in morphological variables that would otherwise be dismissed because they correlate poorly with body mass alone. Therefore, multiple regression is probably the best methodology for using several measures in order to compensate for the influence of phylogeny or specific functional adaptations. In this way, multiple regression functions can be considered as mathematical algorithms (i.e. detailed sequences of actions performed to accomplish some task) that allow one to estimate the mass of past species (body mass determination algorithms).

In the book edited by Damuth \& MacFadden (1990), only two authors, Damuth (1990) and Jungers (1990), propose algorithms generated through multiple regression analysis, although other researchers have explored its use (Anderson, Hall-Martin \& Russell, 1985; Hammer \& Foley, 1996; Biknevicius, 1999; Palmqvist, Arribas \& MartínezNavarro, 1999; Palmqvist et al., 2002; Payseur et al., 1999). However, the data sets used in these studies do not include a wide set of measures and species. In addition, in most cases the predictor variables were selected before the derivation of the regression functions, which did not take advantage of the abilities of this technique for selecting the best combination of variables.

In this paper we examine different strategies for minimizing the effects of the phylogenetic legacy and ecological adaptations on the correlation between the body mass of ungulates and their craniodental morphology, in order to obtain mathematical algorithms with the greatest predictive 
power for estimating the mass of extinct species. We predict that those species with a common phylogenetic legacy or that share similar ecological adaptations will show a greater morphological similarity to each other and that, when analyzed separately from other ungulates, their craniodental dimensions will show a higher correlation with body mass. With this in mind, the predictive ability of regression functions adjusted using a restricted taxonomic clade (e.g. bovids), or with species that share the same ecological adaptation (e.g. grazers), is tested against those functions derived from a more taxonomically or ecologically diverse group. Additionally, other factors such as the method of selection of variables and the relation between the number of variables involved in the regression functions to the number of species used for their derivation are also analyzed. Finally, taking into account the results of these tests, we develop a set of algorithms that use different combinations of craniodental variables for estimating the mass of ungulates and apply them to three extinct North American species whose feeding habits were inferred by Mendoza, Janis \& Palmqvist (2002): the equid Dinohippus leidyanus, the camelid Stenomylus hitchcocki and the dromomerycid Aletomeryx scotti. Dinohippus is a common late Miocene through early Pliocene ( 11.5-3.2 Ma) monodactyl horse with a facial morphology and dentition that place it as the sister taxon to Equus (MacFadden, 1998). This equid has usually been considered to be a grazer, because of its high degree of hypsodonty, but results obtained from dental microwear (Solounias \& Semprebon, 2002) and carbon isotopes (MacFadden, Solounias \& Cerling, 1999) have been interpreted as indicative of a mixed feeding or even a browsing diet. The discriminant functions derived in a comparative analysis of craniodental morphology in ungulates unequivocally classified D. leidyanus as a grazer, although this study also revealed that $D$. leidyanus probably incorporated more browse in its diet than extant horses (Mendoza et al., 2002). Stenomylus is a late Oligocene through early Miocene ( 30.0-16.5 Ma) 'gazelle camel' with the lower incisors, canine and first premolar forming a row of closely spaced, spatulate teeth and third molars that are elongated anteroposteriorly and extremely hypsodont, features that have led some workers to consider it to be a grazer (Honey et al., 1998). However, it also has a very narrow muzzle, and existed before the extensive spread of grasslands in North America; thus it would more likely be a mixed feeder, as indicated by discriminant analysis (Mendoza et al., 2002). Finally, Aletomeryx is an early Miocene ( 23.5-16.5 Ma) genus of the cervid-related family Dromomerycidae, whose members are usually considered to be browsers. However, Aletomeryx is more hypsodont than other species in this family. In addition, it is the only species where horns are apparent in both sexes, which among modern ungulates is indicative of an open habitat existence, and its fairly long and slender metapodials are also suggestive of a preference for open habitats (Janis \& Manning, 1998). This is confirmed by the comparative study of the craniodental structure of $A$. scotti, which is typical of a mixed feeder (Mendoza et al., 2002). According to micro- wear and mesowear analyses of molar teeth, this species has been characterized as a mixed feeder/grazer (Semprebon, Janis \& Solounias, 2004).

\section{Methods}

\section{Data}

Multiple regression analyses were performed using the logtransformed mass and 25 craniodental measures (Fig. 1, Table 1, Supplementary Material Appendix S1) of 138 ungulate species, representing all living ungulate genera. Dental variables included the lengths and widths of the fourth lower premolar and all lower molars, and of the upper second molar. Most skull measures taken were length variables, rather than width variables, owing to the difficulty in obtaining undistorted measurements on fossil skulls (see Janis, $1990 a, b)$. The average masses of ungulate species were obtained from Kingdon (1979), Nowak (1999) and Janis (1995).

In order to determine the predictive power of the regression functions over new species not used in their derivation, 20 test species were excluded from a preliminary set of analyses. The algorithms finally proposed for the estimation of the body mass of extinct ungulates were derived from the complete database.

Fourteen families of terrestrial ungulates are present in the original data set, although these families contain very different numbers of species. Bovids (72 species) and cervids

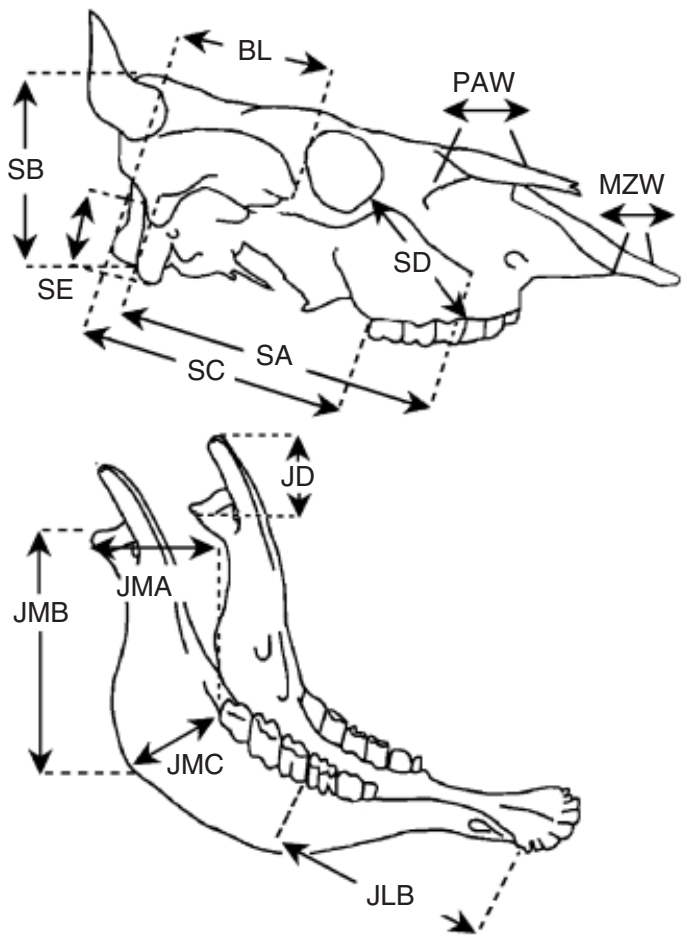

Figure 1 Some craniodental measurements used in this study (see Table 1 for a description of the variables). 
Table 1 Description of craniodental variables used in this study

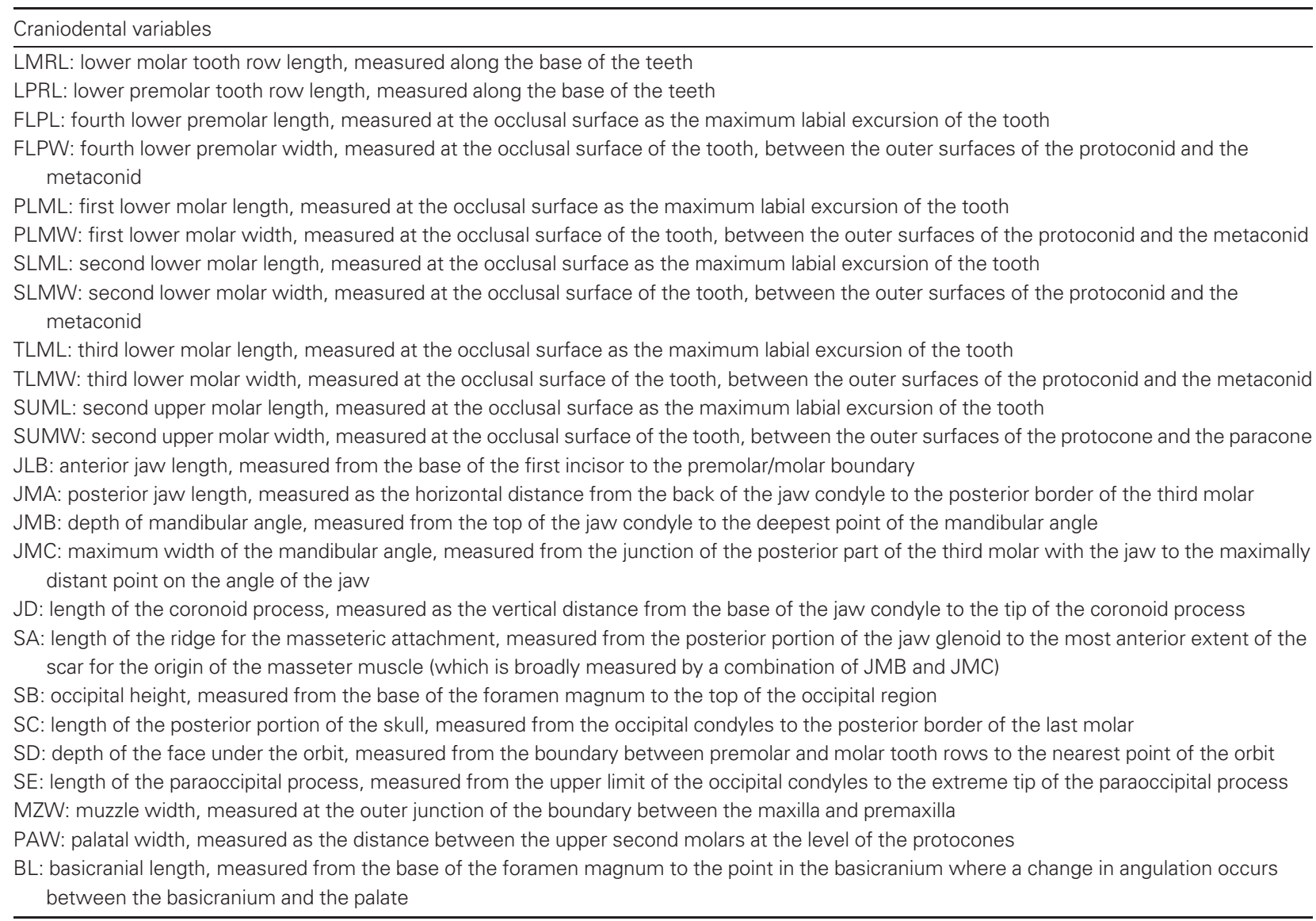

(24 species) are over-represented, whereas families such as antilocaprids or moschids are under-represented. The family Antilocapridae includes only one species, Antilocapra americana, whereas the family Moschidae has several species, of which we have sampled only one, Moschus moschiferus. The 20 test species include six bovids, ranging in mass from 6 to $611 \mathrm{~kg}$, two cervids and 12 species representing each of the remaining families. Because $A$. americana and $M$. moschiferus are two species of the 20 test species, the sample used to perform the preliminary analyses does not include species from these families. This allows testing the predictive power of the regression functions over ungulate species from families not represented in the sample used to obtain them.

\section{Selection of variables}

Multiple regression has often been applied following the direct method, which incorporates all the variables analyzed in the function. However, this procedure has several limitations. For a start, it is never a good strategy to include many variables, especially when the number of samples (i.e. species in our case) is not very large, and it is particularly inappropriate to use those variables that do not make a significant contribution to the correlation (Norusis, 1988).
In fact, increasing the number of variables $(V)$ artificially increases the percentage of variance explained, because the determination coefficient $\left(R^{2}\right)$ expected from a set of random numbers is $V /(N-1)$ (Darlington, 1990). Thus, an increase of the variance explained is not always translated to an improvement of the resulting algorithm. On the other hand, the samples do not contribute equally in the determination of the multiple regression functions, because different subsets of a taxonomically homogeneous species (e.g. subspecies or even individuals of different sexes) may operate, to a certain extent, as a single sample. In such cases, increasing the number of species entails a spurious improvement of the correlation, and the assumptions on phylogenetic independence are violated (Cheverud, Dow \& Leutenegger, 1985; Felsenstein, 1985; Harvey \& Pagel, 1991; Garland \& Ives, 2000). In any case, given that even different species may not represent independent samples of a statistical distribution because of their phylogenetic interrelationships (see Felsenstein, 1985; Harvey \& Pagel, 1991), statistical analysis, sensu stricto, cannot be performed. Thus, statistical probabilities and confidence intervals must be considered with a degree of scepticism in such studies. In this paper, the accuracy of the resulting functions is evaluated directly from their predictive power over the 
20 test species, using the mean per cent prediction error $(\% \mathrm{PE})$ of mass estimates after transformation to nonlogarithmic data $[\% \mathrm{PE}=$ (predicted mass-observed mass $) /$ observed mass $\times 100]$ as an inverse estimate of their predictive power.

In order to minimize the effects of phylogeny, it is important to maximize the taxonomic diversity of the sample in terms of the number of groups (i.e. ungulate families) analyzed and the evenness of their representation. Although the number of taxonomic groups is limited by the sample available, their taxonomic evenness can be statistically adjusted. The species of those subgroups under-represented in the sample can be weighted with respect to the ones that are more represented, keeping the total number of samples constant. To adjust the evenness at the family level, for example, the weighting value of each species belonging to a given family must equal the mean number of species per family (number of species/number of families) divided by the number of species belonging to this family. In this way, the final weight of each family in the analysis is the same. However, such weighting could be considered as a violation of the assumptions of phylogenetic independence, as those species from the less diverse families are over-weighted. However, given that confidence intervals and other statistics of the regression functions are not directly applied to the predictions for extinct ungulates, weighting the species does not invalidate the results obtained. In fact, the differential weighting of the taxonomic groups is another of the factors analyzed in this paper.

Because a great amount of the information contained in the predictor variables is redundant, different combinations of these morphological variables can characterize the body size of a given group of species. Thus, given that the multiple regression function will not include all morphological variables but different combinations of them, the aim of this study is to find the best combinations for predicting body mass. This is not a simple problem, as it concerns not only mathematicians but also scientists from other disciplines (e.g. Darlington, 1990; Draper \& Smith, 1998; Maxwell, 2000). In fact, there is no unique solution for finding the best combination of predictor variables, apart from testing all of them, which is usually not practicable given that for $n$ variables the number of possible combinations is $2^{n-1}$. The program SPSS offers different possibilities for selecting the variables, but only two of them are tested here: the backward and stepwise methods. The stepwise procedure seems, a priori, the one of most obvious use, as it selects the independent variable best correlated with body mass and, after incorporating it within the regression function, searches among the others for the variable that accounts for more variance of the independent variable not explained by others previously included in the function. In this way, the variable included at each step is the one that shows a lowest $P$ value $\left(p_{\text {in }}\right)$ or $F$ probability (i.e. conditional probability of a random relationship between the dependent and predictor variables). After the inclusion of each new variable in the regression function, the $P$ values of the variables already included change. When one of them exceeds a limit established previously ( $p_{\text {out }}$ or $F$ probability for being excluded), this variable is eliminated from the function. The process stops when no variable can be added or eliminated, because none of the variables included in the function exceed the $p_{\text {out }}$ value and all variables that were not included exceed the $p_{\text {in }}$ value. In contrast, the backward method begins by incorporating all the variables in the regression function and then excludes at each step the one with a highest $p_{\text {out }}$ value. The process stops when no included variable exceeds the $p_{\text {out }}$ value established before analysis. Frequently two or more variables correlate jointly with body mass, but only when one of them is included in the function the others become significant. In such cases, only the backward method can identify these sets of variables.

\section{Organization of the analyses}

Three sets of analyses were performed for statistical testing. The first was carried out without taxonomic or ecological restrictions, using the 138 species from the database (118 species for deriving the preliminary functions and 20 for testing their predictive power). Regression functions were obtained both by unweighted data and by weighting the species according to diversity at the family level. These analyses were also performed by limiting the morphological variables to different parts of the craniodental structure, such as the jaw, the skull or the lower teeth. The second set of analyses was performed with taxonomic restrictions, using the 72 bovid species (66 species for determining the functions and six for testing them) and also the same number of ungulate species selected randomly. Finally, the third set of analyses was made from species that share the same feeding adaptations, one subset with grazers and the other with browsers. The grazing category (bulk feeders) includes those species that predominantly feed on grass throughout the year whereas the browsing category (selective feeders) groups those ungulates whose food is mainly composed of leaves. Both groups are defined as different from mixed feeders, which feed on both grass and dicotyledonous plants, depending on their availability. Although there are some species whose feeding classification is not unequivocal, it is presumed that the diversity of feeding strategies and craniodental morphologies in both sets of species (i.e. grazers and browsers) will be lower than in the whole set of ungulates. This allows analyzing the effects of a decrease in the feeding diversity of ungulates on the resulting regression functions.

Each set of analyses entails the application of the functions obtained using the backward and stepwise methods for selection of variables to the test species. The analyses performed with the backward method were carried out using extremely low $p_{\text {out }}$ values, which ended with the rejection of all variables. These analyses were performed for evaluating which variables characterize the regression functions with the highest predictive power. All functions, from the first one (that includes the 25 morphological variables) to the last one (that involves only one variable), were applied to the 20 test species, which provided estimates 
of the mean per cent prediction error (MPE) of each function with species not used in their derivation. This protocol allowed us to identify which factors determine the predictive power of those algorithms generated by multiple regression analysis between body mass and craniodental measures.

\section{Algorithms proposed and inferences on extinct taxa}

The information resulting from the test analyses was taken into account for obtaining the definitive regression functions with all the species available. These functions allowed the estimation of the body mass of the three extinct ungulate species, D. leidyanus, S. hitchcocki and A. scotti. However, as the specimen of $A$. scotti used in this work lacks the upper molar teeth, some algorithms that involve morphological variables measured in these teeth could not be applied to this species.

\section{Results and discussion}

\section{Factors that determine the predictive power of the algorithms}

\section{Analysis of the methods for selection of variables and effects of species weighting}

An initial analysis was carried out without taxonomic or ecological restrictions using the backward method and weighting the species by families. During the sequence of exclusion of variables, a gradual increase is observed in the predictive power of the functions (denoted by a decrease of MPE) from the one with 18 variables to the best equation, which involves only six variables (black circles, Fig. 2). At this stage, there is a clear relationship between the MPE value of each function and the significance of the variables involved. For example, the function with 18 variables has MPE of $\sim 13.5 \%$, involving seven non-significant variables $(P>0.05)$. However, the function with 12 variables (MPE $\sim 7.5 \%$ ) incorporates only one non-significant variable, and all the variables within the function with 10 variables (MPE $\sim 6.5 \%)$ are statistically significant $(P<0.05)$. In the best function, with six variables (MPE $\sim 4.5 \%$ ), all of them are very significant $(P<0.001)$. From that point onwards, however, these very significant variables are gradually removed, the value adjusted for $R^{2}$ falls (black dots, Fig. 2) and the mean prediction error increases dramatically to $30 \%$ (Fig. 2).

The regression functions that incorporate between 25 and 11 variables explain a high percentage of variance of body mass, but they all involve several non-significant variables, whose contribution to the correlation is probably random. The functions that involve fewer than five variables, however, incorporate only very significant variables but explain a considerable lower variance of body mass, as estimated by their low $R^{2}$ values (black dots, Fig. 2). Thus, the functions that show the highest predictive power include from 10 to

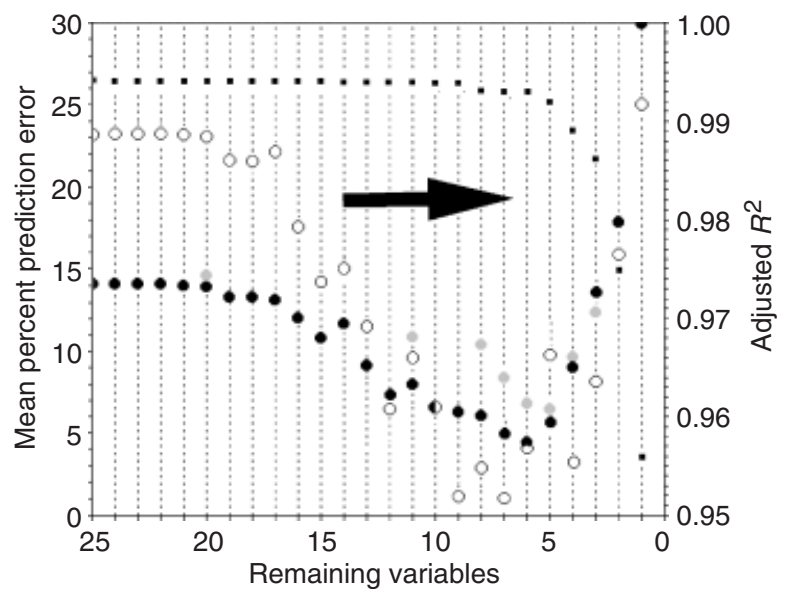

Figure 2 Change of the mean per cent prediction error (\%MPE, circles) in the estimation of body mass throughout different sequences of multiple regression analyses (backward method) performed without taxonomic or ecological restrictions (filled circles: \%MPE with the 20 test species; empty circles: \%MPE with the two test species from families not represented in the sample) and change of the adjusted $R^{2}$ values (right, dots). Gray circles: partial representation of the change of \%MPE with the 20 test species but with the analysis conducted using unweighted species.

five variables, all of them statistically significant $(P<0.05)$, and they explain the highest percentages of variance. These functions, which change according to the specific analysis and are expected to show the highest predictive power, will be identified in what follows as backward significant range.

The precision of the mass estimates obtained when these regression functions are applied over the two test species whose families are not represented in the sample (antilocaprids and moschids) is similar to the one recorded for the rest of the species. This confirms the predictive power of these algorithms. However, the highest predictive ability for these test species is obtained by other functions of the backward significant range. The best results are obtained with those functions involving seven and nine variables (empty circles, Fig. 2), instead of the function with six variables. However, given that these are only two test species, these results are more probably affected by their particular craniodental features.

Weighting the families according to their diversity improves the predictive abilities of the resultant functions. Specifically, the best function adjusted with unweighted species shows an MPE value of 6.6\% (gray circles, Fig. 2), whereas the best algorithm obtained with weighting the species gives an MPE value of only $4.5 \%$ (filled circles, Fig. 2). In addition, the weighting procedure provides a wider range of functions showing high predictive power: that is, a wider backward significant range.

As was expected, the same analyses performed with morphological variables from different parts of the craniodental structure, such as the jaw, the skull or the lower teeth, always resulted in a lower predictive power for the particular regression function derived. The best function obtained by 
the backward method with jaw and dental measures provided an MPE value of $\sim 13.5 \%$, which rises to $\sim 21 \%$ if only jaw measures are taken into account. Using only skull variables, including the dimensions of the second upper molar, an MPE value of $\sim 13.5 \%$ was obtained. However, when upper tooth measures were not included, the predictive power decreased to $\sim 17.5 \%$. Finally, analyses performed with only measures of the lower teeth resulted in algorithms with the least predictive power, as MPE represented $\sim 21 \%$. In all these cases, the best results were also obtained by the backward significant range of functions.

Taking into account the results obtained by the backward method, the analyses performed by the stepwise procedure were carried out weighting the species according to family diversity and using values of $p_{\text {in }}$ and $p_{\text {out }}$ that allow the direct derivation of a function whose variables are very significant $(P<0.01)$. The resultant function, in this case, was the same as the best function generated using the backward method. The first function obtained throughout the process of analysis by the stepwise method (MPE of $\sim 22.5 \%$ ) involves only the variable best correlated with body mass (the second upper molar width) and shows lower prediction ability than all the functions of the backward significant range. Thus, the use of multiple regression represents an evident methodological improvement with respect to simple regression approaches. However, very similar results (MPE of $\sim 23 \%$ ) were obtained with those functions involving a high number of non-significant variables for the two test species whose families are not represented in the sample (empty circles, Fig. 2), in spite of the fact that the percentage of variance explained by these functions is almost $100 \%$.

\section{Analysis of the taxonomic restriction and effects of decreasing the number of species}

The first subset of these analyses was again performed with the 72 bovid species available and using the backward method for selection of variables; 66 species were used in the derivation of the functions and six for testing them. Throughout the process of elimination of variables (gray circles, Fig. 3), the increase in predictive power started this time with seven variables (MPE of $\sim 14 \%$ ) and finished with the best function, which involved only three variables (MPE $\sim 9 \%$ ), although the function that incorporated two variables shows a similar predictive power (MPE of $\sim 9.5 \%$ ). In this case, there was also a close relationship between the mean per cent prediction error of the resultant functions and the significance of the variables involved in them. The first function that only incorporates significant variables $(P<0.05)$ selected four morphological measures, and in the one with two variables both of them are very significant $(P<0.01)$. The adjusted $R^{2}$ value falls with the function that involves only one variable (MPE of $\sim 40.5 \%$ ). Thus, the backward significant range involves only three functions in this case, whose percentages of variance explained are lower than the highest values reached throughout the analysis (black dots, Fig. 3). The analyses performed using the

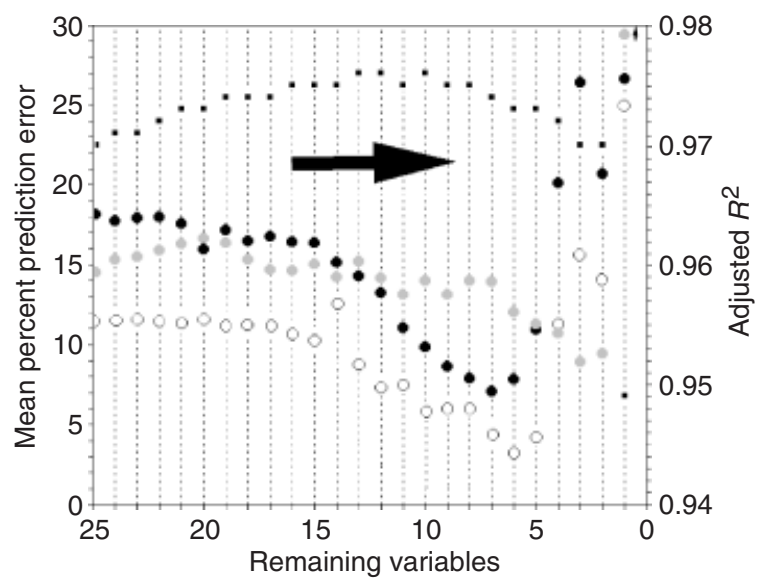

Figure 3 Change in the mean per cent prediction error (\%MPE) with six bovid test species throughout different processes of backward multiple regression analyses (circles) and the adjusted $R^{2}$ values (dots). Gray circles and dots: sample of 66 bovid species; filled circles: sample of 66 ungulate species without taxonomic restrictions; empty circles: sample of 118 ungulate species without taxonomic restrictions.

stepwise method resulted in the same function as the one generated from the backward method involving two variables. These analyses were also performed weighting the species according to the diversity of their tribes, but this did not improve the results obtained.

Contrary to expectations, the taxonomic restriction of the multiple regression analysis to bovid species did not improve the predictive abilities of the resultant algorithms in comparison with the predictions for bovids obtained using those functions adjusted with all ungulate species. In fact, the ability of these algorithms even decreases (MPE of $~ 3.5 \%$ for the best function for ungulates against MPE of $\sim 9 \%$ for bovids; white and gray circles, Fig. 3).

In order to test how the reduction in the number of species translates into a decrease of the predictive power of the regression functions, a second subset of analyses was performed without taxonomic restrictions and using 66 ungulate species randomly selected from the database. As shown in Fig. 3, increasing the taxonomic diversity while keeping the sample size constant improves the predictive power of the resultant functions. However, an important part of the reduction of predictive ability in those functions derived from bovids alone seems to be the consequence of the reduction of sample size. Thus, both factors, diversity and sample size, appear to be important for increasing the predictive abilities of the regression functions. In this case, the best function (MPE of $\sim 7 \%$ ) involves seven variables instead of only two or three, and this is also the case for the best function generated using only bovids (MPE of $\sim 9 \%$ and $9.5 \%$, respectively; black and gray circles in Fig. 3).

\section{Analysis of ecological restrictions}

Again, contrary to expectations, the ecological restriction to grazing or browsing species did not improve the predictive 
power of the algorithms. The best regression function of those obtained for grazers (26 species) with the backward method shows an MPE value of $\sim 29.5 \%$ with the three grazing species used as test samples. These results improve up to an MPE value of $\sim 24 \%$ with the best function obtained using the stepwise method, and increase to $\sim 22 \%$ MPE if the species are weighted by families. These functions involve two variables in the three cases. In any case, all these values are far from the MPE of $\sim 3 \%$ obtained for the same three grazing species used as test samples with the best function of those obtained without ecological or taxonomic restrictions.

The best function of those derived for browsers (37 species) with the backward method and weighting the species according to the diversity at the family level shows an MPE of $\sim 16.5 \%$ when applied to three test browsing species. The improvement with respect to the functions obtained with grazers could be due to the higher number of species and taxonomic diversity of browsers. While 17 out of 26 grazers are bovids, seven are equids, one is a rhino and another one is a suoid, among the browsers there are nine families with different number of species. In spite of this, the predictive ability of these functions is also clearly lower than the one of those obtained without ecological and taxonomic restrictions, among which the best shows an MPE of $\sim 4 \%$ with the same three browsing species used as test samples.

\section{Proposed body mass algorithms}

The algorithms proposed for the estimation of body mass in ungulates are listed in Table 2. These multiple regression functions are classified according to the group of craniodental variables used for their derivation. The range of mean per cent prediction errors ( $\% \mathrm{MPE})$ for the backward significant range of regression functions recorded in the test analyses is also shown. The algorithms were obtained using all of the 138 ungulate species available. According to the expectations from the results obtained in the test analyses, the increase in sample size and diversity translates into a higher predictive power of the regression functions, although such predictive power cannot be tested directly now. The preliminary results obtained with the test analyses were taken into account for developing the definitive set of algorithms, and the complete data set was used without any taxonomic and ecological restrictions. In addition, the taxonomic evenness was maximized to the family level. Finally, the stepwise and backward methods of selection of variables were used, although most of these algorithms were obtained using the latter method. Before applying the backward method, a check analysis was performed using an extremely low $p_{\text {out }}$ value, in order to appreciate the changing values of the statistical significance of the variables incorporated into the regression functions and the changes in the value adjusted for $R^{2}$. Only those functions from the backward significant range that include very significant variables and explain the highest values of variance were selected. The stepwise method was performed using values of $p_{\text {in }}$ and $p_{\text {out }}$ that led to the direct derivation of a function whose variables are very significant $(P<0.01)$. Only those functions obtained with the stepwise method that were different from the ones generated by the backward method and that showed similar values of variance explained were selected; they are marked in Table 2 with an asterisk. Given that the algorithms included in Table 2 were obtained from the same database and weighting the species according to the diversity at family level, their adjusted $R^{2}$ values (also included in Table 2) are fully comparable (see Methods).

\section{Inferences about extinct taxa}

According to the results obtained in the test analyses, those algorithms derived from the full craniodental structure provide the most consistent estimates of body size for extinct taxa. According to these algorithms, the mass of the late Miocene equid D. leidyanus was around $200 \mathrm{~kg}$ and the masses of both the late Oligocene to early Miocene camelid $S$. hitchcocki and the early Miocene dromomerycid A. scotti approached $30 \mathrm{~kg}$ (Table 2).

\section{Discussion}

The main methodological conclusion of this article is that multiple regression techniques represent a clear improvement over single regression methods in the derivation of algorithms that allow the estimation of body mass in extinct ungulates from their craniodental structure. The predictive power of the best function that combines craniodental measures (MPE of $\sim 4.5 \%$ ) is five times higher than the one obtained with the single variable (the second upper molar width) that shows the best correlation with body mass (MPE of $\sim 22.5 \%$ ).

Given the information available (i.e. the set of ungulate species and morphological variables), the functions with highest predictive power are those that incorporate only significant predictor variables $(P<0.05)$ and explain a relatively high value of the variance of the dependent variable (body mass).

Contrary to the expectations, limiting the data set used in the adjustment of the multiple regression functions to a taxonomically or ecologically homogeneous group does not improve the predictive ability of the resulting algorithms; rather, the predictive power of these equations decreases. In the case of those functions obtained by simple regression, an increase in the morphological diversity translates in the obtaining of larger standard errors, which in turn results in equations with lower predictive power. Using the multiple regression approach, however, the highest predictive power is obtained with those algorithms derived from the entire set of ungulate species, a procedure that maximizes the taxonomical and ecological diversity of the database. This indicates that, contrary to the simple regression method, the diversity of the sample analyzed is a key factor for obtaining reliable algorithms with multiple regression techniques. However, the higher the diversity of the sample studied, the higher the number of variables involved in those functions showing 


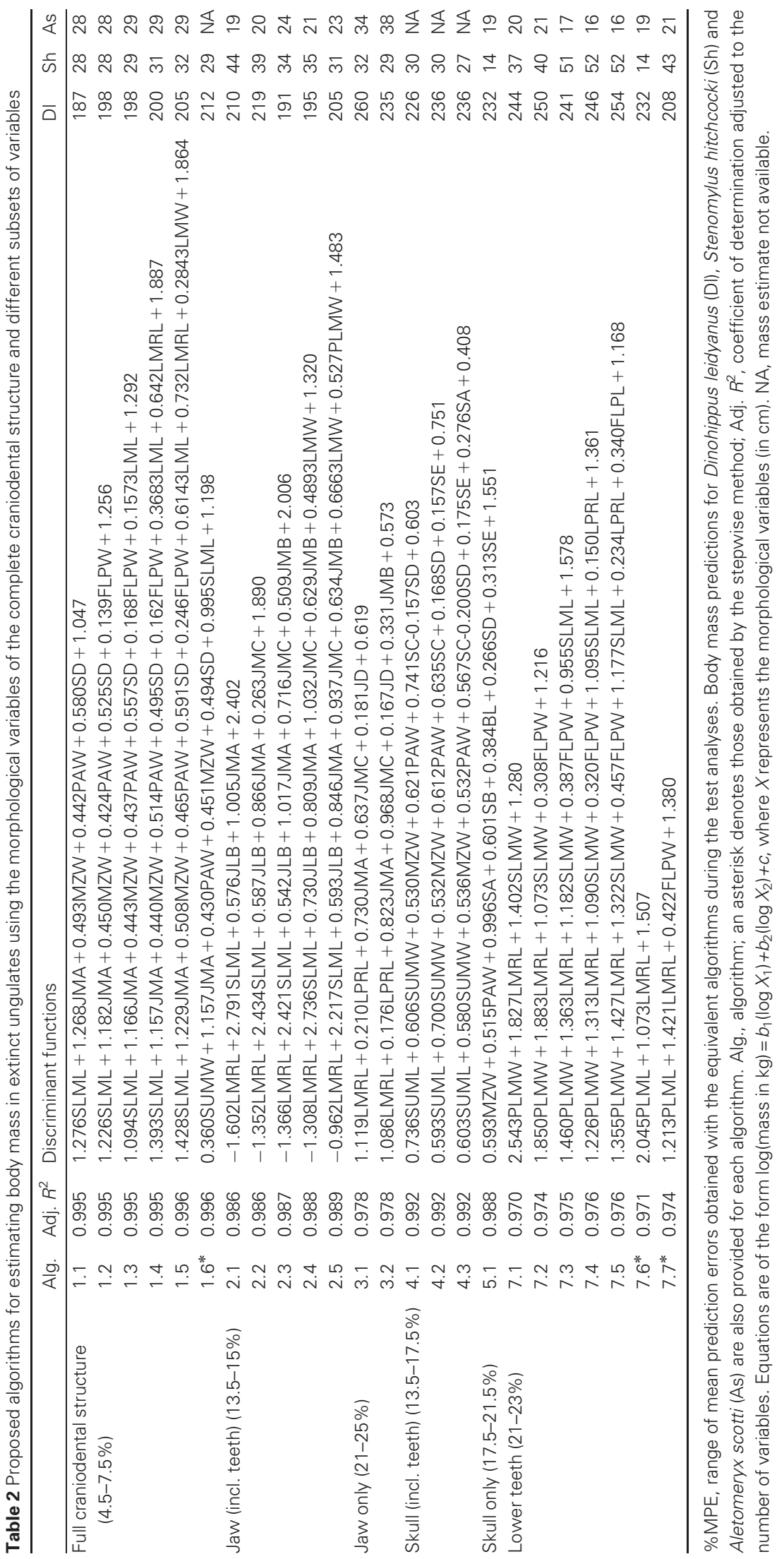


more predictive power. In a diverse ungulate sample, such as the one used in this study, phylogenetic and adaptive factors pose severe constraints on the variability of craniodental morphology; in such a case, it is expected that a large number of variables will be necessary for compensating these biases.

Any algorithm that allows the characterization of the mass of mammalian species provides useful information about the functional relationship between aspects of skeletal morphology and body size. If sample size and the number of predictor variables are both increased, the amount of information available about these relationships will be greater. This may be the reason why the diversity and morphological disparity of the data set of ungulate species analyzed here are fundamental factors for obtaining reliable algorithms.

The diversity of a given set of species can be maximized by increasing the taxonomic evenness at family level by the differential weighting of those species belonging to ungulate families with low diversity, which in turn increases the predictive ability of the resulting algorithms. The predictive power of the best function obtained from the complete set of craniodental variables and weighting the species according to the diversity at family level (MPE of $\sim 4.5 \%$ ) is only 1.5 times greater than the best obtained with an unweighted adjustment (MPE of $\sim 6.6 \%$ ), but the backward significant range of functions with higher predictive power is noticeably broader.

The different components of the craniodental structure of ungulates show different predictive abilities for deriving algorithms that provide inferences on the body mass of extinct ungulates. As was expected, the range of $\% \mathrm{MPE}$ of the backward significant range of functions is minimum (4.5-7.5\%) using the full craniodental structure. Using variables from the jaw and lower teeth only, this range increases to $13.5-15 \%$, and with only variables from the jaw the range rises to $21-25 \%$. Using variables from the skull and the second upper molar, the mean per cent prediction errors of the backward significant range of functions range from 13.5 to $17.5 \%$, but this error increases to $17.5-21.5 \%$ if the second molar is not used. Finally, using only the lower tooth measurements as variables, the MPE range varies from 21 to $23 \%$.

The body mass inferences are around $200 \mathrm{~kg}$ for D. leidyanus and around $30 \mathrm{~kg}$ for both $S$. hitchcocki and A. scotti. These results are similar to the average masses estimated by Janis $(1990 a, b)$ from simple regressions adjusted with the same database used here and compare well with the mass estimates obtained by Scott (1990) from limb measurements: $218 \mathrm{~kg}$ of average mass (range of values: 98-283 kg) for Dinohippus, $31 \mathrm{~kg}$ (range: 24-42 kg) for Stenomylus and $21 \mathrm{~kg}$ (range: 14-36) for Aletomeryx.

In the few cases in which a complete skeleton is available for a given extinct species and a reliable estimate of the total volume of the animal may be calculated, the mass estimates obtained from multiple regression equations can be compared with the ones provided by other approaches, such as scale models of life appearance restorations or the method of cylinders (e.g. Fariña et al., 1998). The main problem with these approaches is the lack of any external reference to know which methodology provides the most reliable estimates of body mass. In the approach developed here, however, there is always the possibility to compare the mass predictions of the multiple regression equations over extant species not used in their adjustment with the actual masses of these test species; of course, this is an indirect way for contrasting the inferences on extinct species.

Given that the three extinct species analyzed in this work belong to taxonomic groups that are included in the sample of ungulate species used to perform the statistical analyses, it is expected that the prediction errors for these species will fall within the same range of the ones obtained with the test species. These prediction errors could even be lower, given that the estimates were obtained with the definite algorithms, which were generated with 20 species more than in the case of the preliminary regression functions adjusted for checking the mass estimates for the 20 test species.

According to the values of body mass of extant ungulate species provided by different authors, the range of values that can be deduced from the best algorithms do not depart significantly from the intraspecific body mass ranges. Thus, the only way to enhance the results obtained with this methodology is to use measures and body mass values from individuals instead of species averages (provided a sample with similar number of species and taxonomic diversity).

\section{Acknowledgements}

One of the authors (M. M.) was funded by postdoctoral grants from the Spanish CICYT and the Fulbright Visiting Scholar Program. We gratefully acknowledge insightful remarks from B. Martinez-Navarro and one anonymous reviewer.

\section{References}

Alexander, R.McN., Jayes, S.A., Maloiy, G.M.O. \& Wathuta, M.E. (1979). Allometry of the limb bones of mammals from shrews (Sorex) to elephant (Loxodonta). J. Zool. (Lond.) 189, 305-314.

Anderson, J.F., Hall-Martin, A. \& Russell, D.A. (1985). Long-bone circumference and weight in mammals, birds and dinosaurs. J. Zool. (Lond.) 207, 53-61.

Andersson, K. (2004). Predicting carnivoran body mass from a weight-bearing joint. J. Zool. (Lond.) 262, 161-172.

Anyonge, W. (1993). Body mass in large extant and extinct carnivores. J. Zool. (Lond.) 231, 339-350.

Beard, K.C., Tong, Y., Dawson, M.R., Wang, J. \& Huang, X. (1996). Earliest complete dentition of an anthropoid primate from the Late Middle Eocene of Shanxi Province, China. Science 272, 82-85.

Biewener, A. (1982). Bone strength in small mammals and bipedal birds: do safety factors change with body size? J. Exp. Biol. 98, 289-301. 
Biknevicius, A.R. (1999). Body mass estimation in armoured mammals: cautions and encouragements for the use of parameters from the appendicular skeleton. J. Zool. (Lond.) 248, 179-187.

Calder, W.A. (1984). Size, function and life history. Cambridge, MA: Harvard University Press.

Cartelle, C. \& Hartwig, W.C. (1996). A new extinct primate among the Pleistocene megafauna of Bahia, Brazil. Proc. Natl. Acad. Sci. USA 93, 6405-6409.

Cheverud, J.M., Dow, M.M. \& Leutenegger, W. (1985). The quantitative assessment of phylogenetic constraints in comparative analyses: sexual dimorphism in body weight among primates. Evolution 39, 1335-1351.

Christiansen, P. (1999). What size were Arctodus simum and Ursus spelaeus (Carnivora: Ursidae)? Ann. Zool. Fenn. 36, 93-102.

Christiansen, P. (2004). Body size in proboscideans, with notes on elephant metabolism. Zool. J. Linn. Soc. 140, 523-549.

Christiansen, P. \& Fariña, R.A. (2003). Mass estimation of two fossil ground sloths (Mammalia, Xenarthra: Mylodontidae). Senckenbergiana Biol. 83, 95-101.

Damuth, J. (1990). Problems in estimating body masses of archaic ungulates using dental measurements. In Body size in mammalian paleobiology: 229-253. Damuth, J. \& MacFadden, B.J. (Eds). Cambridge: Cambridge University Press.

Damuth, J. \& MacFadden, B.J. (1990). Body size in mammalian paleobiology: estimation and biological implications. Cambridge: Cambridge University Press.

Darlington, R.B. (1990). Regression and linear models. New York: McGraw-Hill.

Delson, E., Terranova, C.J., Jungers, W.L., Sargis, E.J., Jablonski, N.G. \& Dechow, P.C. (2000). Body mass in Cercopithecidae (Primates, Mammalia): estimation and scaling in extinct and extant taxa. Anthropological papers, Number 83. New York: American Museum of Natural History.

Draper, N.R. \& Smith, H. (1998). Applied regression analysis. 3rd edn. New York: John Wiley and Sons.

Fariña, R.A., Vizcaino, S.F. \& Bargo, M.S. (1998). Body mass estimations in Lujanian (Late Pleistocene-Early Holocene of South America) mammal megafauna. Mastozool. Neot. 5, 87-108.

Felsenstein, J. (1985). Phylogenies and the comparative method. Am. Nat. 125, 1-15.

Flynn, J.J., Wyss, A.R., Charrier, R. \& Swisher, C.C. (1995). An early Miocene anthropoid skull from the Chilean Andes. Nature 373, 603-607.

Gagnon, M. (1997). Ecological diversity and community ecology in the Fayum sequence (Egypt). J. Hum. Evol. 32, 133-160.

Garland, T. Jr \& Ives, A.R. (2000). Using the past to predict the present: confidence intervals for regression equations in phylogenetic comparative methods. Am. Nat. 155, 346-364.
Gebo, D.L., MacLatchy, L., Kityo, R., Deino, A., Kingston, J. \& Pilbeam, D. (1997). A hominoid genus from the early Miocene of Uganda. Science 276, 401-404.

Gingerich, P.D. (1990). Prediction of body mass in mammalian species from long bone lengths and diameters. Contrib. Mus. Pal. Univ. Michigan 28, 79-92.

Gingerich, P.D., Smith, B.H. \& Rossenberg, K. (1982). Allometric scaling in the dentition of primates and prediction of body weight from tooth size in fossils. Am. J. Phys. Anthrop. 58, 81-100.

Hammer, M.L.A. \& Foley, R.A. (1996). Longevity and life history in hominid evolution. J. Hum. Evol. 11, 61-66.

Harvey, P.H. \& Pagel, M.D. (1991). The comparative method in evolutionary biology. Oxford: Oxford University Press.

Honey, J.G., Harrison, J.A., Prothero, D.R. \& Stevens, M.S. (1998). Camelidae. In Evolution of tertiary mammals of North America: 439-462. Janis, C.M., Scott, K.M. \& Jacobs, L.L. (Eds). Cambridge: Cambridge University Press.

Janis, C.M. (1990a). The correlation between diet and dental wear in herbivorous mammals, and its relationship to the determination of diets of extinct species. In Paleobiological evidence for rates of coevolution and behavioral evolution: 241-259. Boucot, A.J. (Ed.). New York: Elsevier.

Janis, C.M. (1990b). Correlation of cranial and dental variables with body size in ungulates and macropodoids. In Body size in mammalian paleobiology: 255-300. Damuth, J. \& MacFadden, B.J. (Eds). Cambridge: Cambridge University Press.

Janis, C.M. (1995). Correlations between craniodental morphology and feeding behaviour in ungulates: reciprocal illumination between living and fossil taxa. In Functional morphology in vertebrate paleontology: 76-98. Thomason, J.J. (Ed.). Cambridge: Cambridge University Press.

Janis, C.M. \& Manning, E. (1998). Dromomerycidae. In Evolution of tertiary mammals of North America: 477-490. Janis, C.M., Scott, K.M. \& Jacobs, L.L. (Eds). Cambridge: Cambridge University Press.

Jungers, W.L. (1985). Body size and scaling of limb proportions in primates. New York: Plenum Press.

Jungers, W.L. (1990). Problems and methods in reconstructing body size in fossil primates. In Body size in mammalian paleobiology: 103-118. Damuth, J. \& MacFadden, B.J. (Eds). Cambridge: Cambridge University Press.

Kappelman, J., Plummer, T., Bishop, L., Duncan, A. \& Appleton, S. (1997). Bovids as indicators of Plio-Pleistocene paleoenvironments in East Africa. J. Hum. Evol. 32, 229-256.

Kay, R.F., Johnson, D. \& Meldrum, D.J. (1998). A new pitheciin primate from the Middle Miocene of Argentina. Am. J. Primatol. 45, 317-336.

Kingdon, J. (1979). East African mammals: an atlas of evolution in Africa. Chicago: Chicago University Press.

Kordos, L. \& Begun, D.R. (2001). Primates from Rudabánya: allocation of specimens to individuals, sex and age categories. J. Hum. Evol. 40, 17-39. 
MacFadden, B.J. (1986). Fossil horses from Eohippus (Hyracotherium) to Equus: scaling, Cope's law, and the evolution of body size. Paleobiology 12, 355-369.

MacFadden, B.J. (1998). Equidae. In Evolution of tertiary mammals of North America: 537-559. Janis, C.M., Scott, K.M. \& Jacobs, L.L. (Eds). Cambridge: Cambridge University Press.

MacFadden, B.J., Solounias, N. \& Cerling, T.E. (1999). Ancient diets, ecology, and extinction of 5-million-year-old horses from Florida. Science 283, 824-827.

Maxwell, S.E. (2000). Sample size and multiple regression analysis. Psychol. Methods 5, 434-458.

McCrossin, M.L. (1994). The phylogenetic relationships, adaptations and ecology of Kenyapithecus. PhD dissertation, University of California, Berkeley.

Mendoza, M. (2004). How communities evolve. Proceedings of the fifth international conference on complex systems, Boston, May 2004.

Mendoza, M. (2005). Paleoautecología de Ungulados: Hacia una caracterización ecomorfológica compleja. Ameghiniana. 42, 233-248.

Mendoza, M., Goodwin, B. \& Criado, C. (2004). Emergence of community structure in land mammal-dominated ecosystems. J. Theor. Biol. 230, 203-214.

Mendoza, M., Janis, C.M. \& Palmqvist, P. (2002). Characterizing complex craniodental patterns related to feeding behavior in ungulates: a multivariate approach. J. Zool. (Lond.) 258, 223-246.

Mendoza, M., Janis, C.M. \& Palmqvist, P. (2005). Ecological patterns in the trophic-size structure of mammal communities: a taxon-free characterization. Evol. Ecol. Res. 7, 505-530.

Norusis, M.J. (1988). SPSSx advanced statistical guide. Chicago: SPSS Inc.

Nowak, R.M. (1999). Walker's mammals of the world. 6th edn. Baltimore and London: Johns Hopkins University Press.

Palmqvist, P., Arribas, A. \& Martínez-Navarro, B. (1999). Ecomorphological study of large canids from southeastern Spain. Lethaia 32, 75-88.

Palmqvist, P., Mendoza, M., Arribas, A. \& Grocke, D. (2002). Estimating the body mass of Pleistocene canids: discussion of some methodological problems and a new 'taxon free' approach. Lethaia 35, 358-360.

Payseur, B.A., Covert, H.H., Vinyard, C.J. \& Dagosto, M. (1999). New body mass estimates for Omomys carteri, a Middle Eocene primate from North America. Am. J. Phys. Anthrop. 109, 41-52.
Peters, R.H. (1983). The ecological implications of body size. Cambridge: Cambridge University Press.

Ruff, C.B. (1987). Structural allometry in femur and tibia in Hominoidea and Macaca, with comparisons to diaphyseal scaling. J. Hum. Evol. 17, 687-714.

Ruff, C.B. (1988). Hindlimb articular surface allometry in Hominoidea and Macaca. Folia Primatol. 48, 9-29.

Ruff, C.B. (1989). New approaches to structural evolution of limb bones in primates. Folia Primatol. 53, 142-159.

Scott, K.M. (1990). Postcranial dimensions of ungulates as predictors of body mass. In Body size in mammalian paleobiology: 301-335. Damuth, J. \& MacFadden, B.J. (Eds). Cambridge: Cambridge University Press.

Semprebon, G., Janis, C.M. \& Solounias, N. (2004). The diets of the Dromomerycidae (Mammalia: Artiodactyla) and their response to Miocene vegetational change. J. Vertebr. Paleontol. 24, 427-444.

Smith, R.J. (1984). Allometric scaling in comparative biology: problems of concept and method. Am. J. Physiol. 246, 152-160.

Smith, R.J. (2002). Estimation of body mass in paleontology. J. Hum. Evol. 42, 271-287.

Solounias, N. \& Semprebon, G. (2002). Advances in the reconstruction of ungulate ecomorphology with application to early fossil equids. Am. Mus. Novit. 3366, 1-49.

Van Valen, L. (1960). A functional index of hypsodonty. Evolution 14, 531-532.

Van Valkenburgh, B. (1990). Skeletal and dental predictors of body mass in carnivores. In Body size in mammalian paleobiology: 181-205. Damuth, J. \& MacFadden, B.J. (Eds). Cambridge: Cambridge University Press.

Viranta, S. (1994). Limb bone proportions and body mass of the cave bear (Ursus spelaeus). Hist. Biol. 7, 239-250.

Walker, A., Teaford, M.F., Martin, L. \& Andrews, P. (1993). A new species of Proconsul from the early Miocene of Rusinga/Mfangano Islands, Kenya. J. Hum. Evol. 25, 43-56.

\section{Supplementary material}

The following material is available for this article online:

Appendix S1 Ungulate species, family, body mass (BM, in $\mathrm{kg}$ ) and 25 craniodental measurements (in $\mathrm{cm}$ ) used in this study (see description in Table 1 and Fig. 1). Asterisks indicate extinct species.

This material is available as part of the online article from http://www.blackwell-synergy.com 


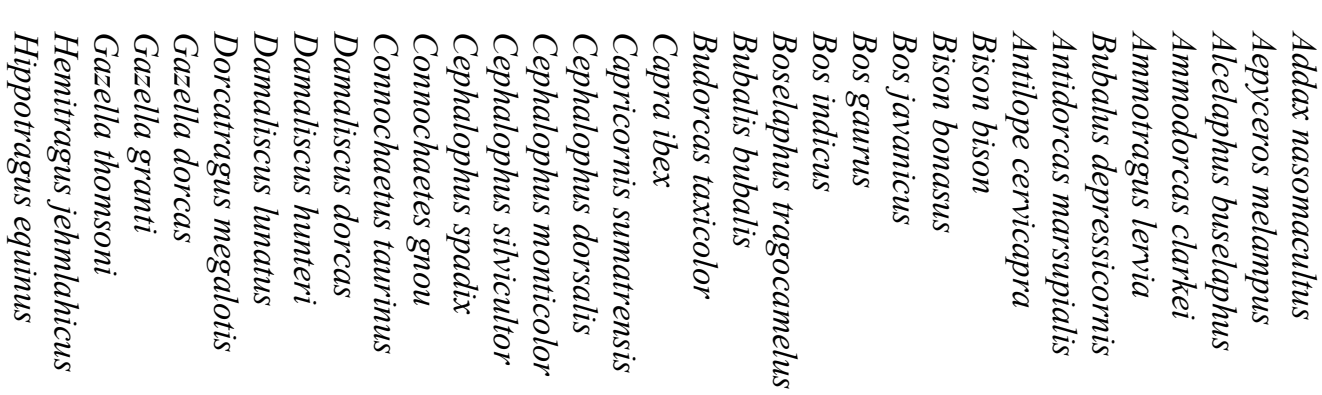

巾

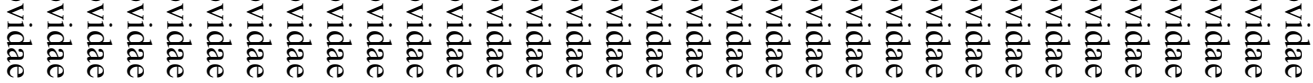

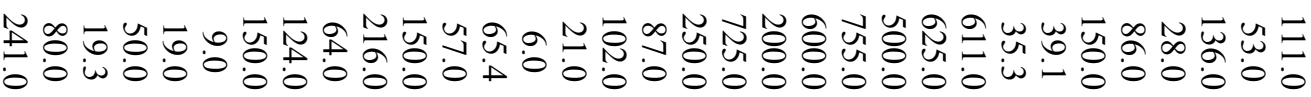

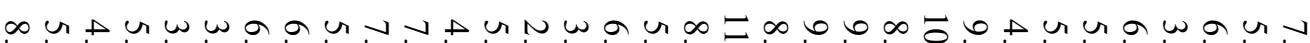

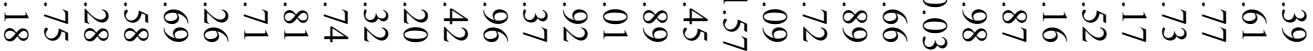

u $N N N N-\omega N \omega N N N A-N \omega N A-A$ u 出

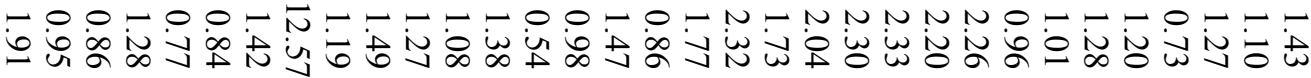
-

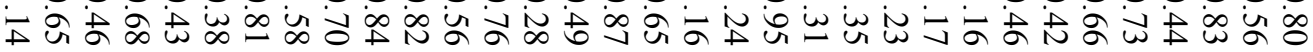

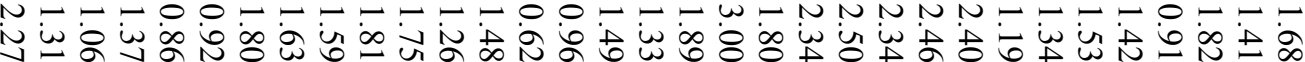

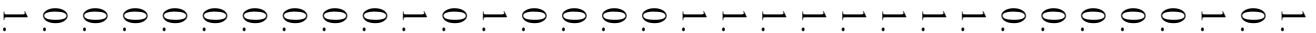

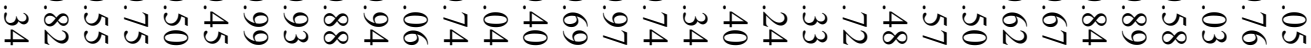

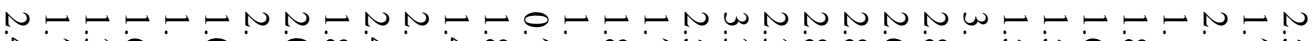

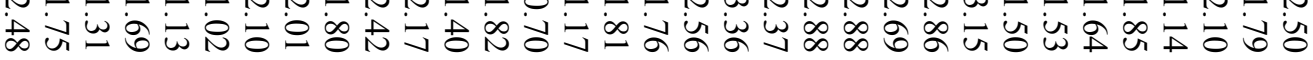

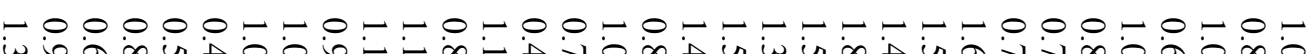

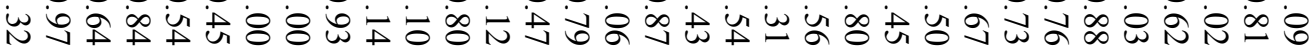

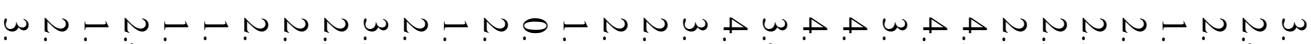

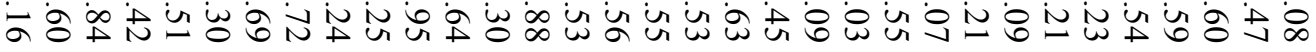

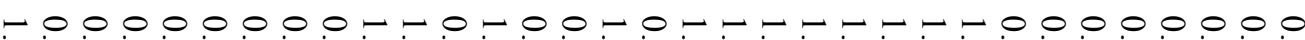
न

$N--1--N \omega-N N--O--T N \omega N N N N N \omega-T-N-N N N$

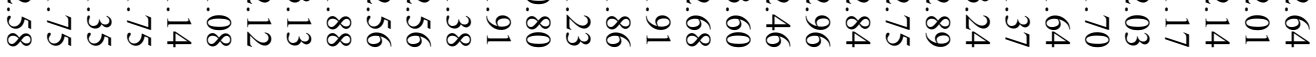




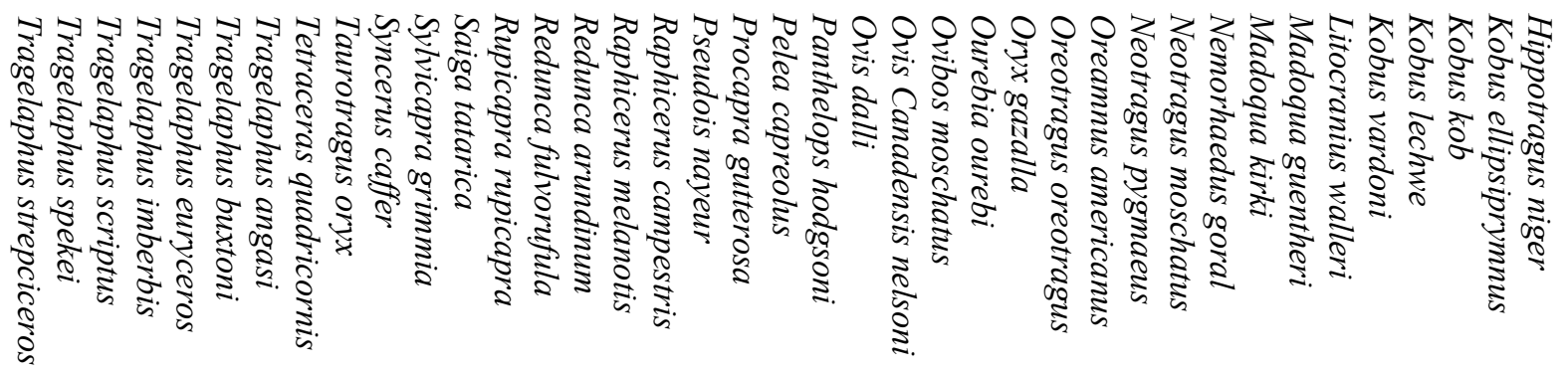

巾

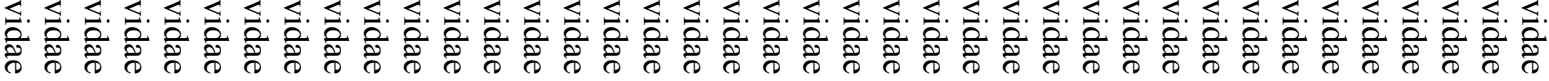

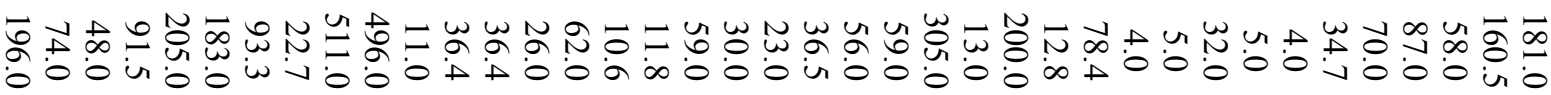

$\infty$ un $\rightarrow$ a 9 un \&

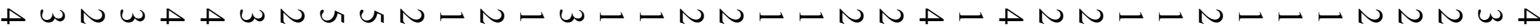

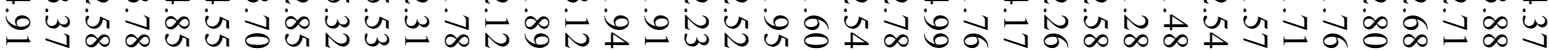

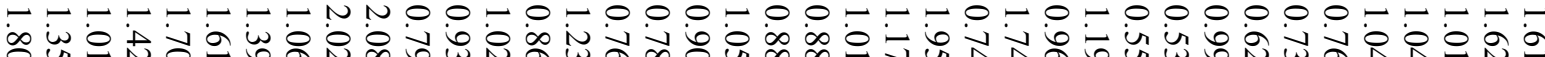

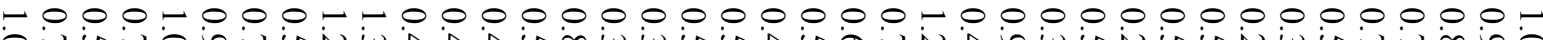

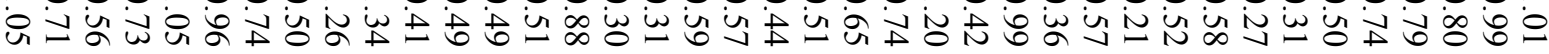

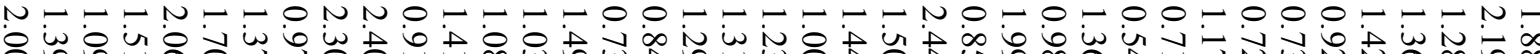
ứ

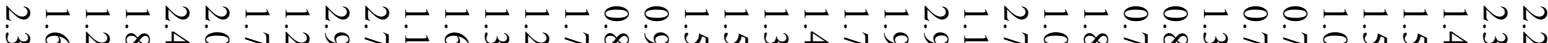

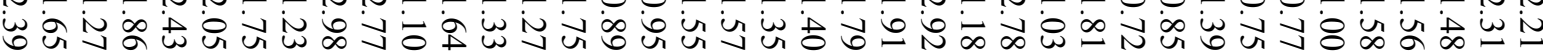

-

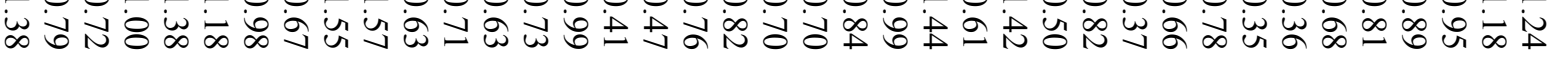

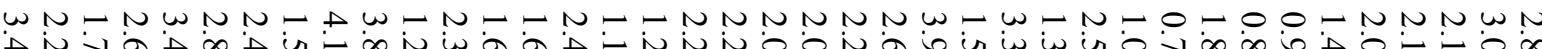

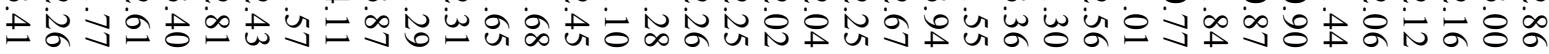

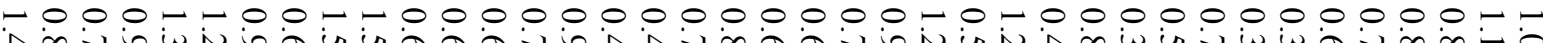

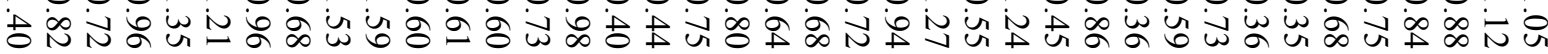

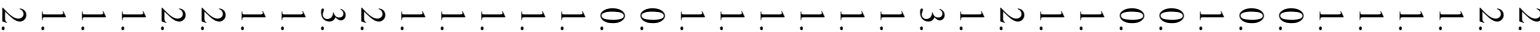

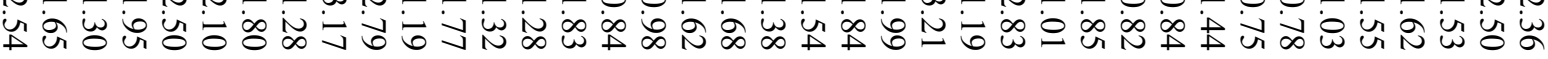




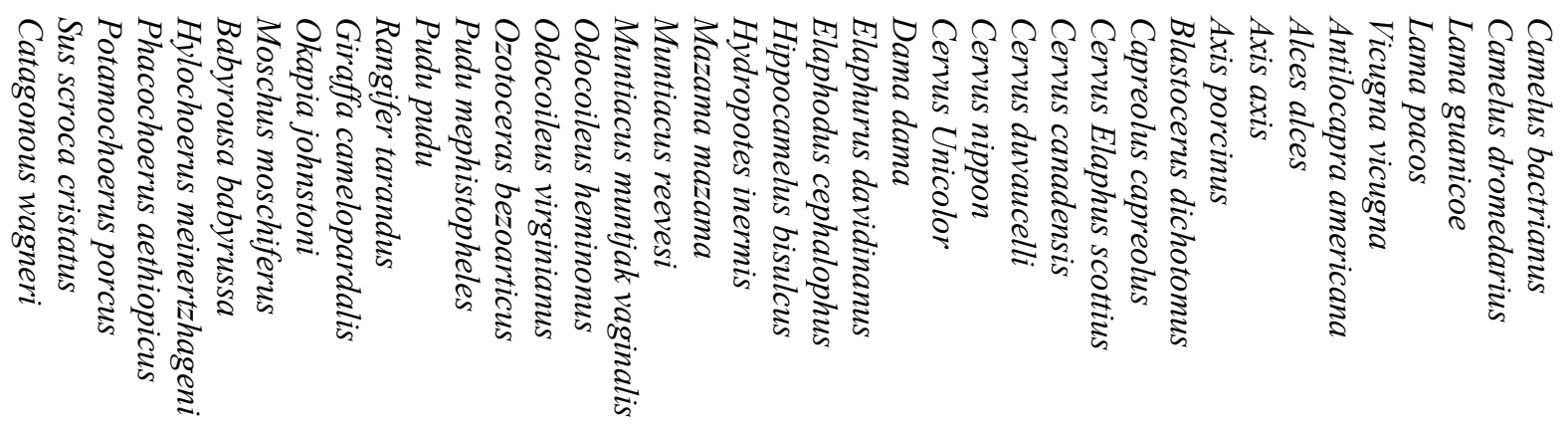

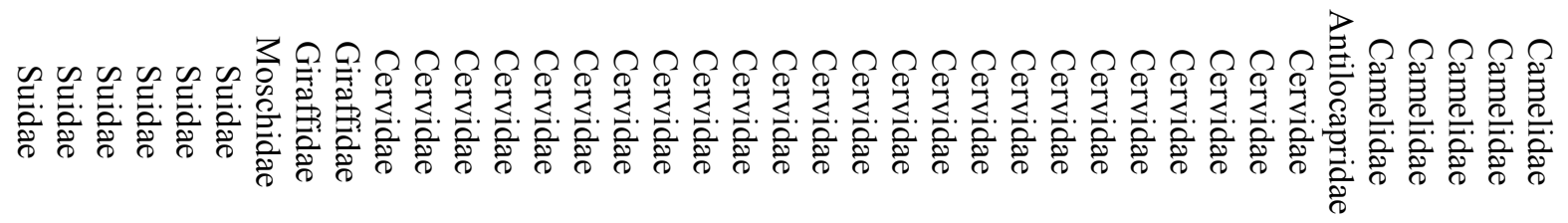

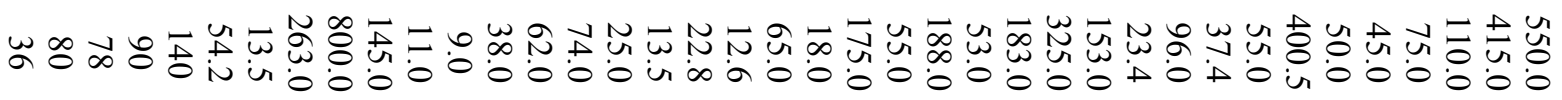

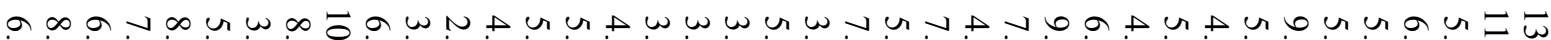

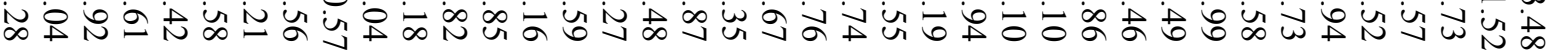

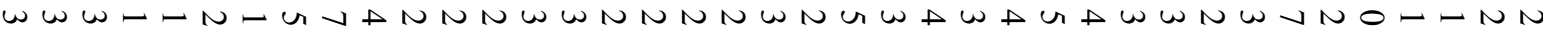

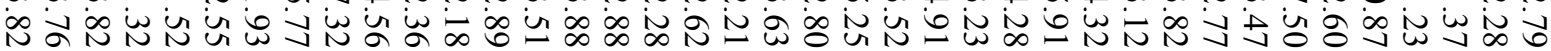

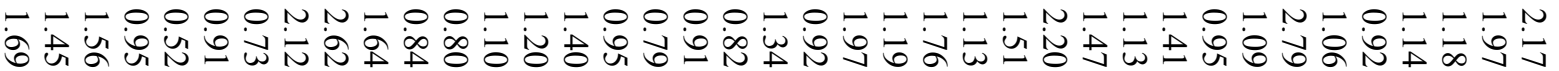

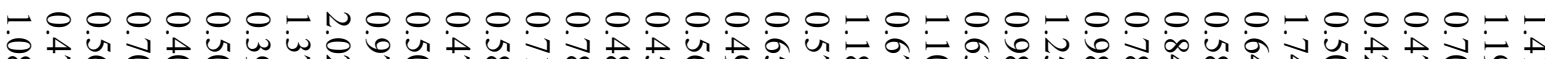

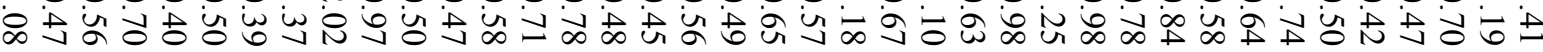

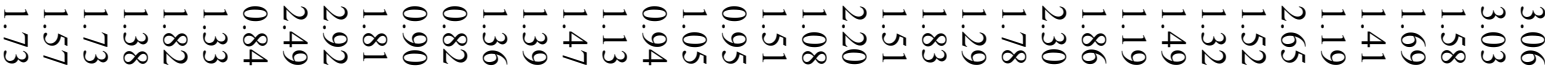
تं宀

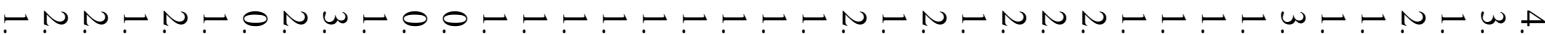

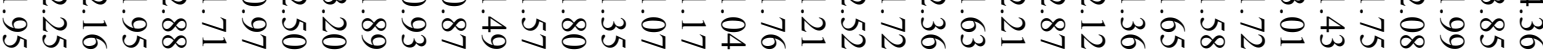

T-

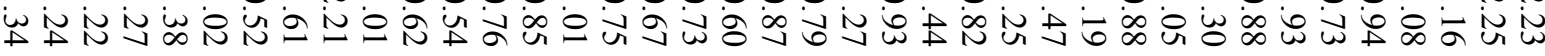

Nan, w N W

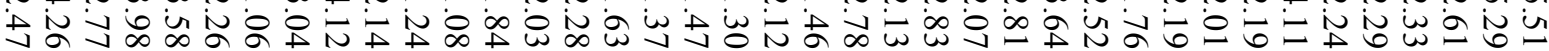

- - - - -

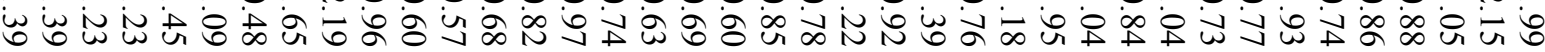

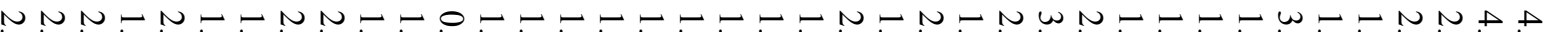

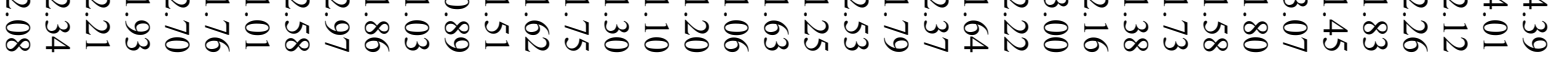




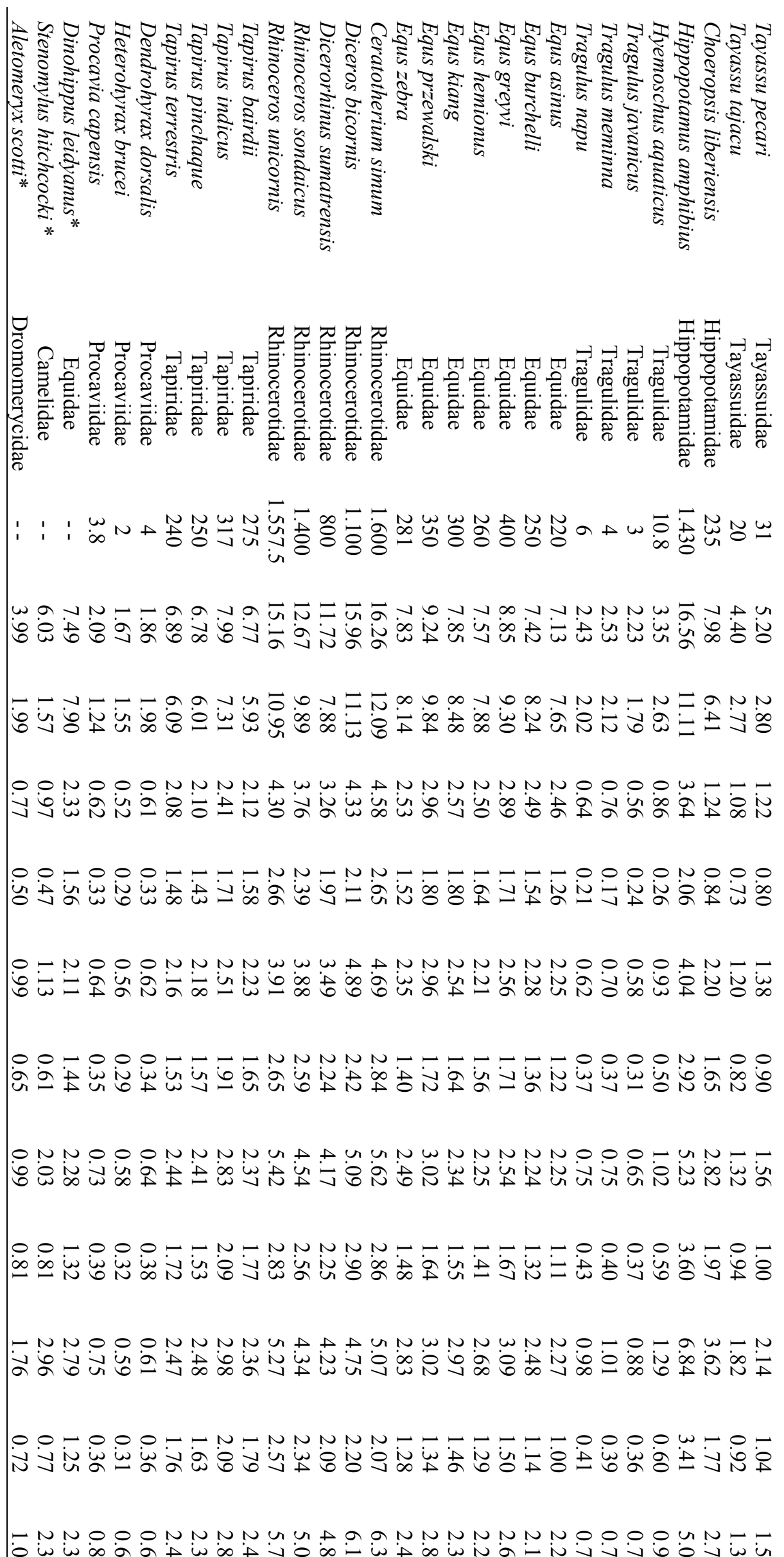

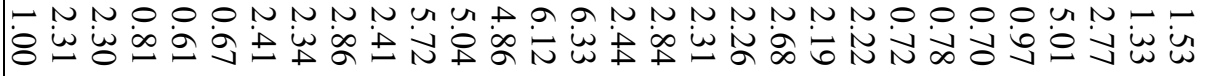




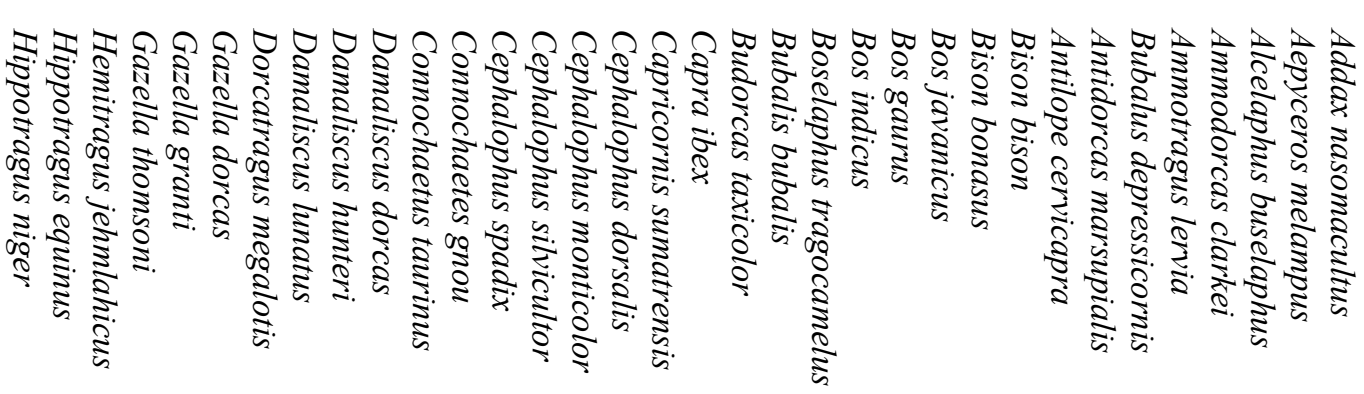

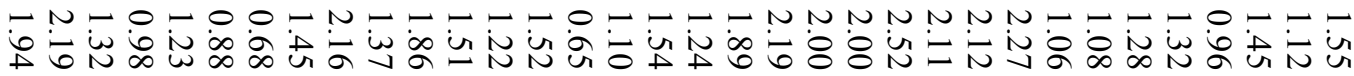

Ғ $\infty \propto \infty$ un

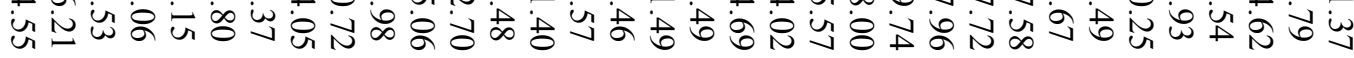

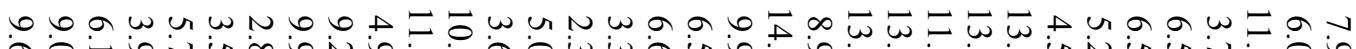

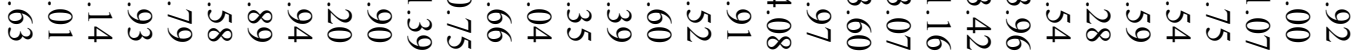

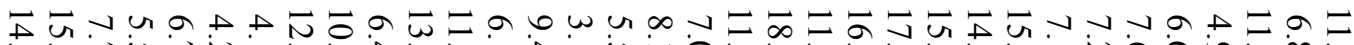

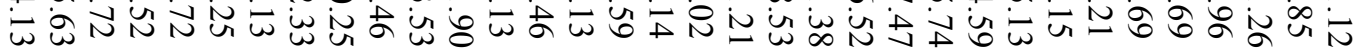

бъи un

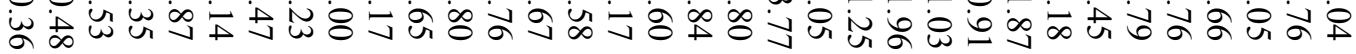

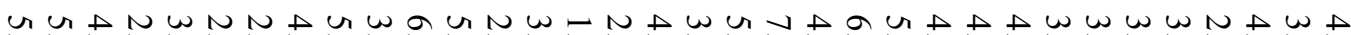

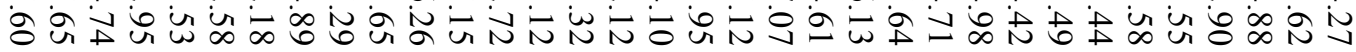

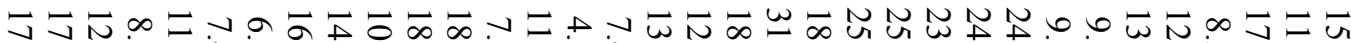

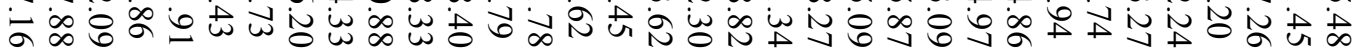
$\infty$ ou

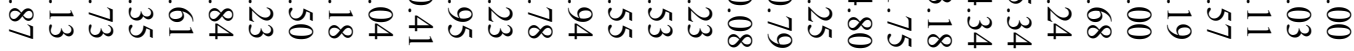

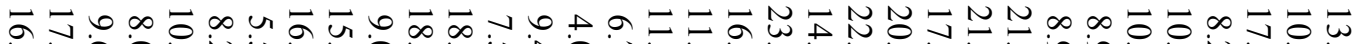

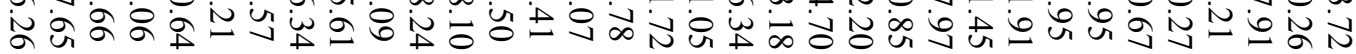

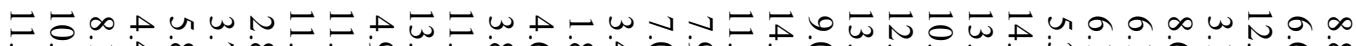

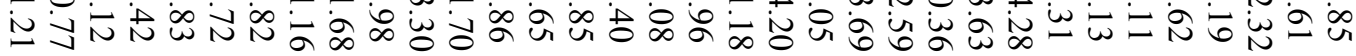

u u

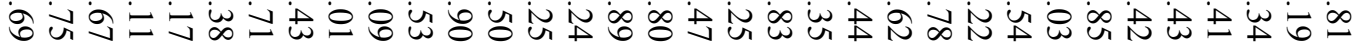

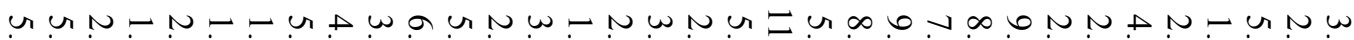

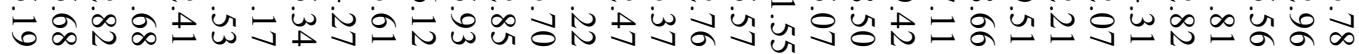

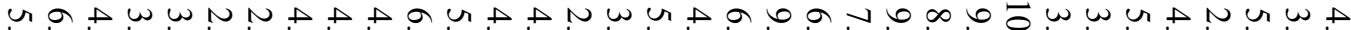

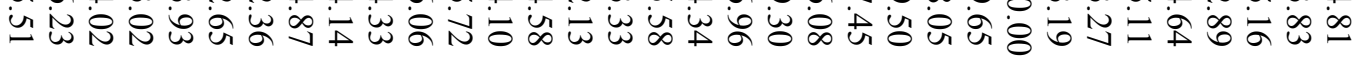

二

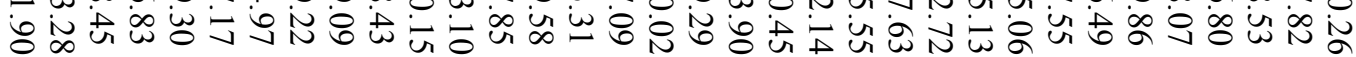




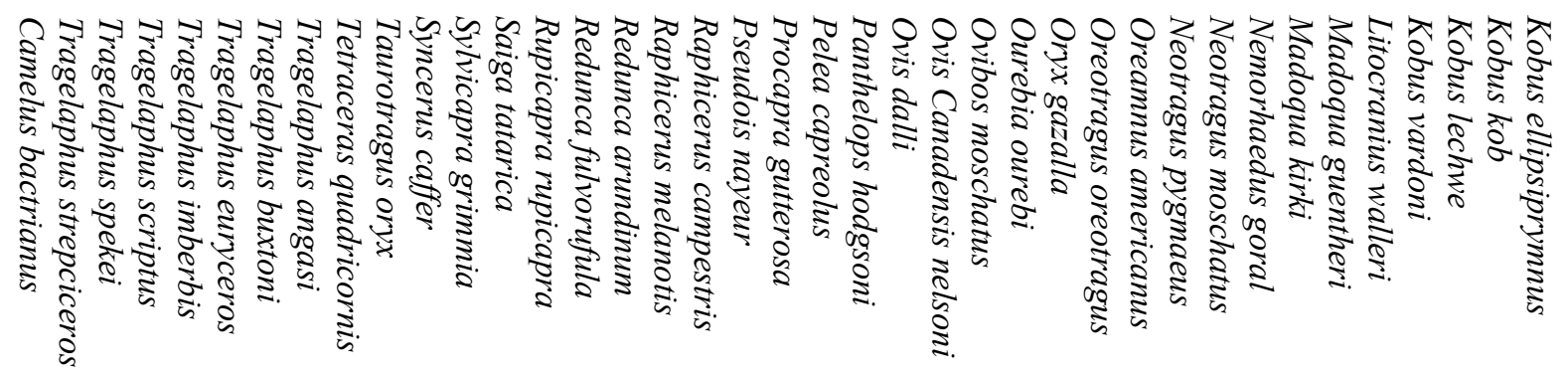

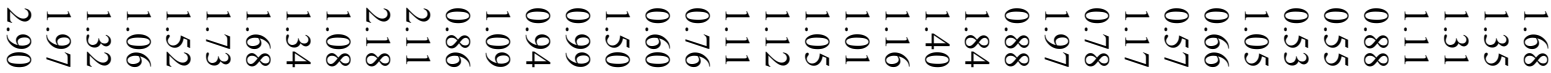

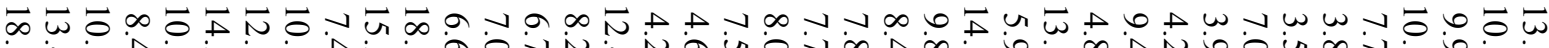

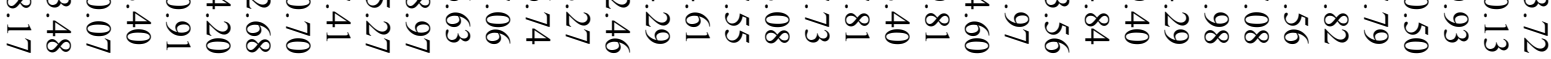

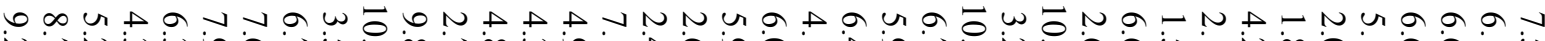

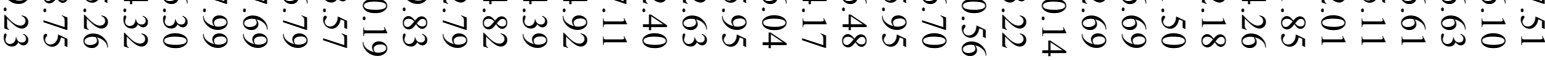

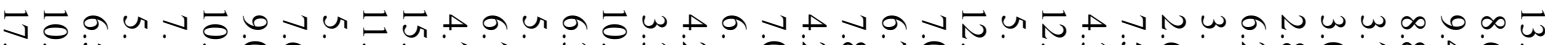

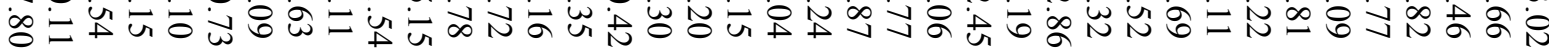

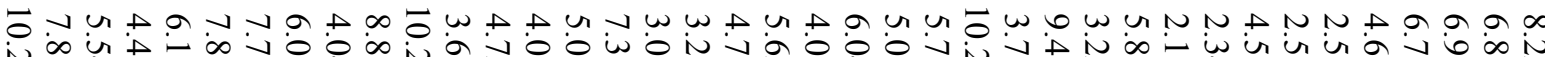

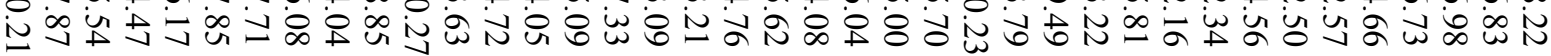

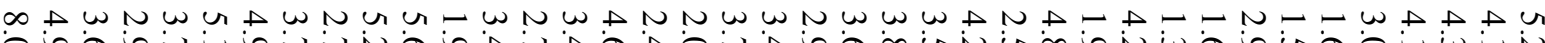

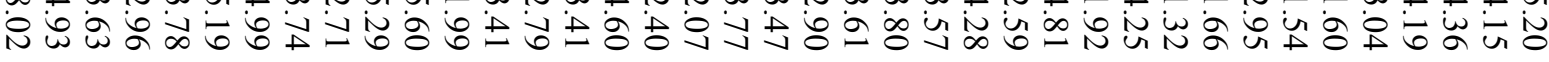

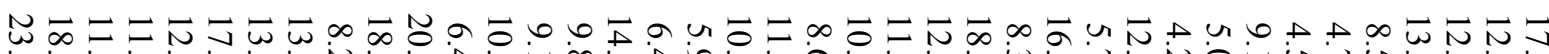

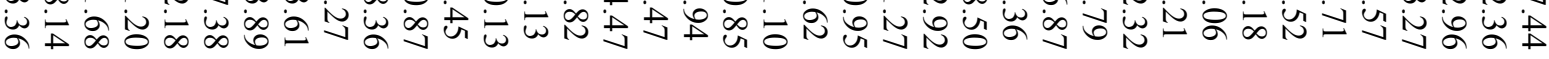

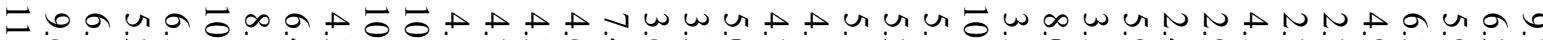

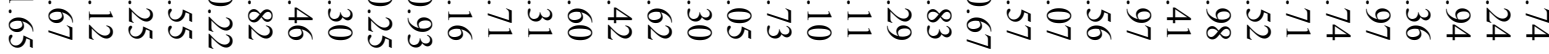

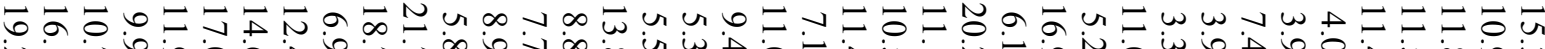

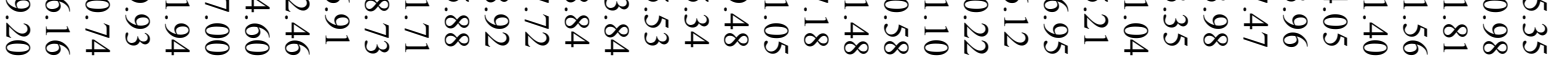

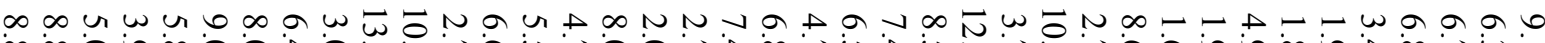

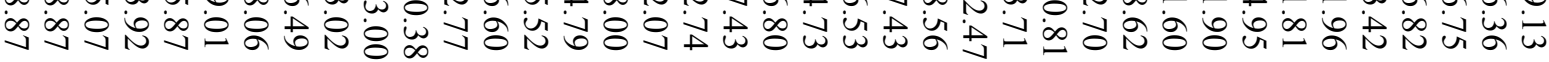

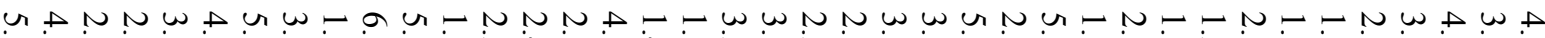

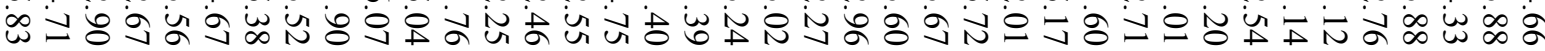

u r u

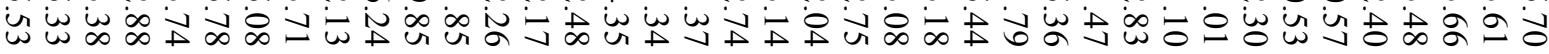

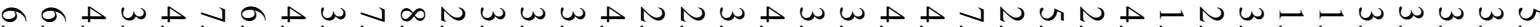

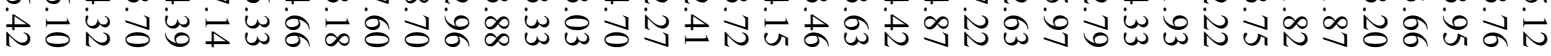

F

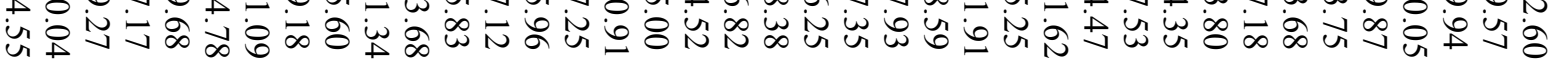




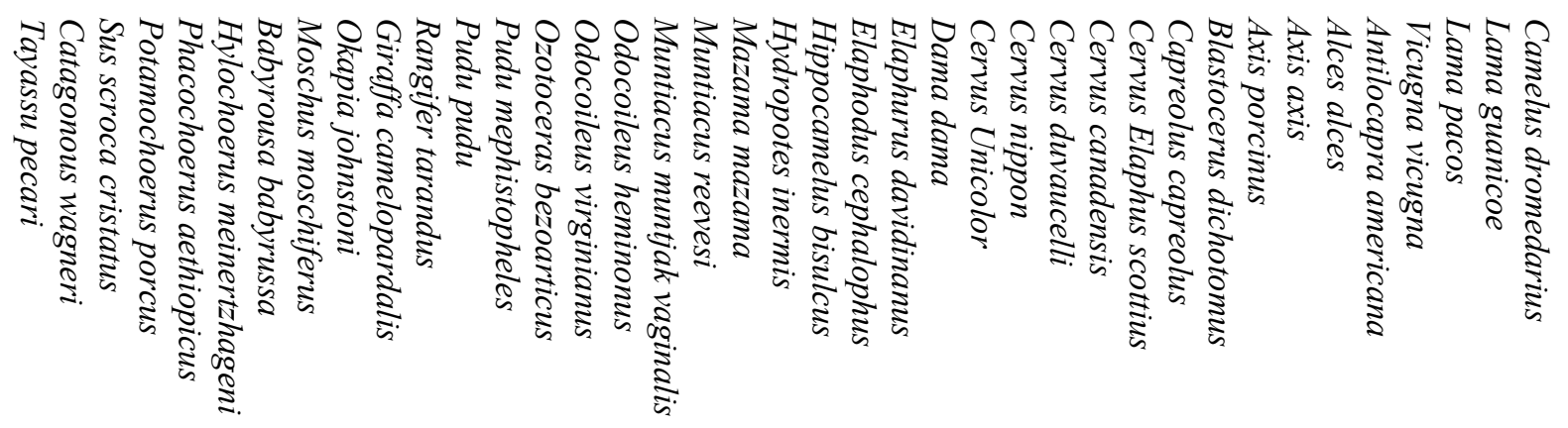

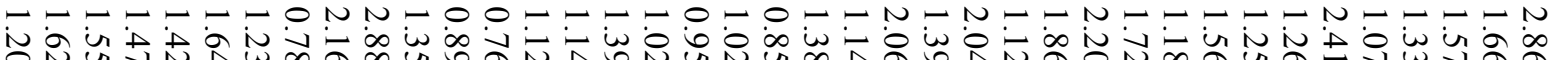
mo:

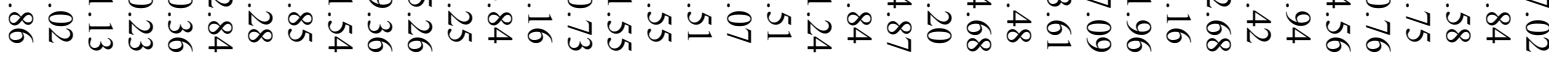

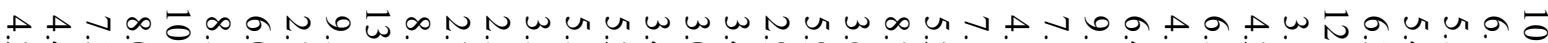

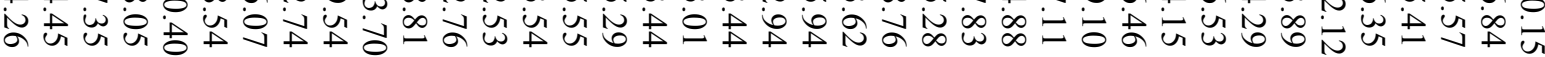

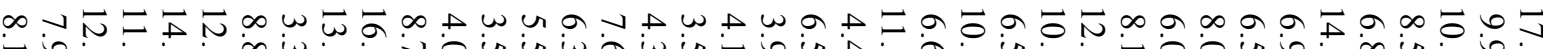

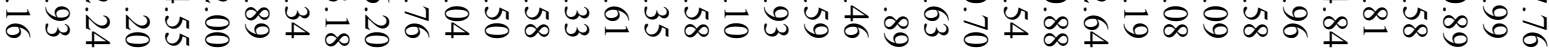

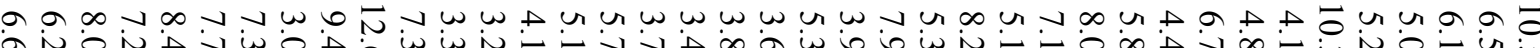

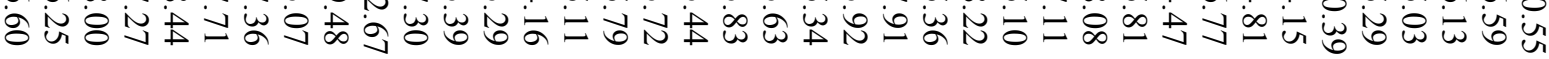

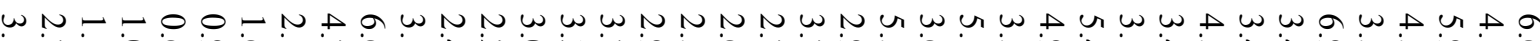
பัง

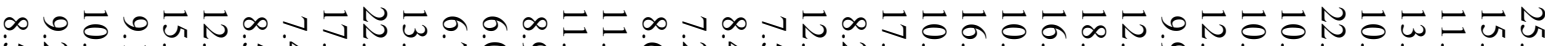

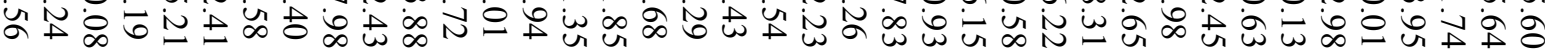

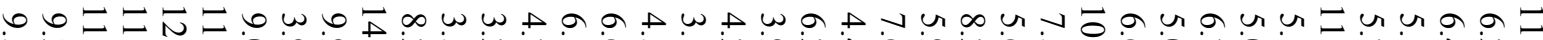

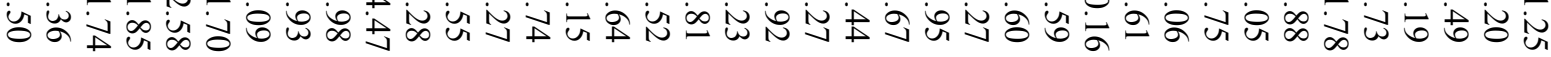

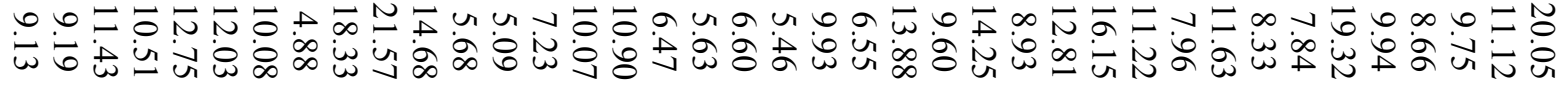

U G

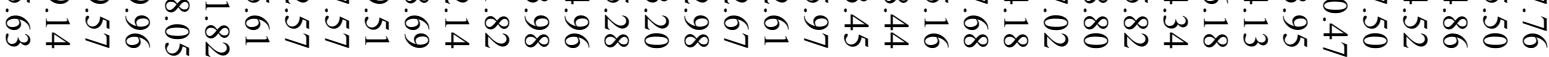

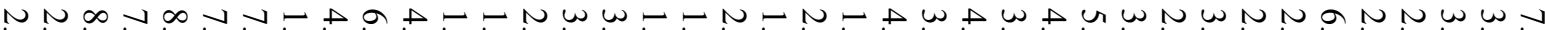

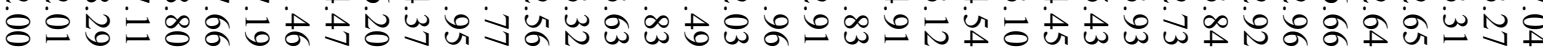

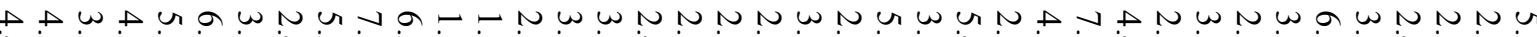

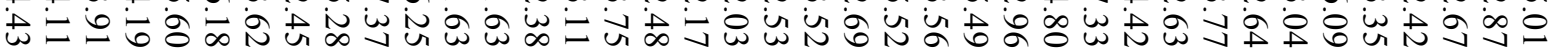

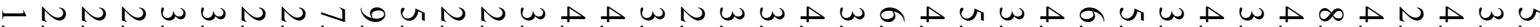

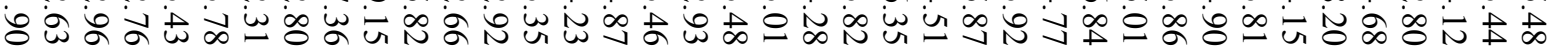

a u二 نू 


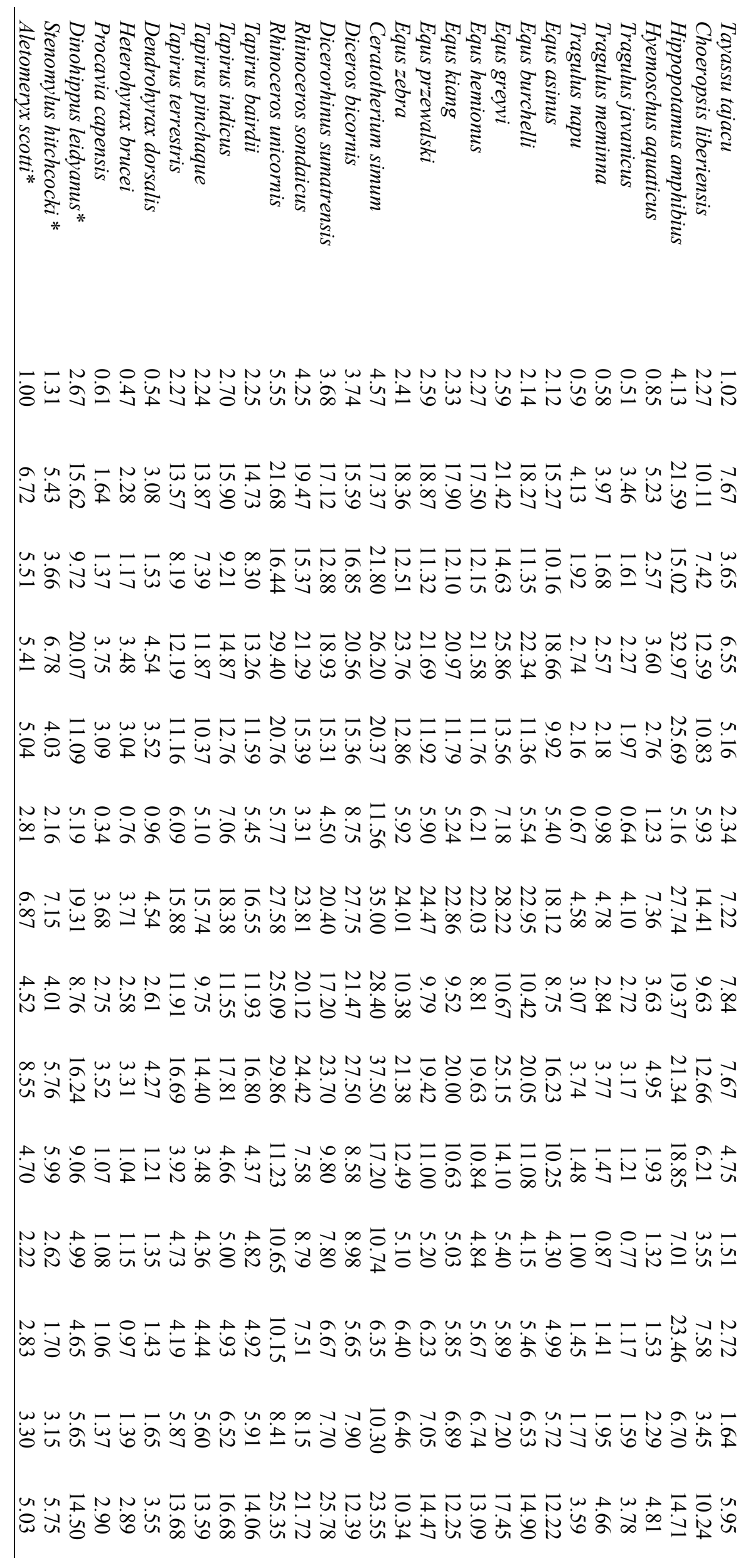

